Earthquake Hazards Geophysical Investigations

\title{
Miscellaneous High-Resolution Seismic Imaging Investigations in Salt Lake and Utah Valleys for Earthquake Hazards
}

Open-File Report 2007-1152 


\section{Miscellaneous High-Resolution Seismic Imaging Investigations in Salt Lake and Utah Valleys for Earthquake Hazards}

By W.J. Stephenson, R.A. Williams, J.K. Odum, and D.M. Worley

Earthquake Hazards Geophysical Investigations

Open-File Report 2007-1152 


\title{
U.S. Department of the Interior DIRK KEMPTHORNE, Secretary
}

\author{
U.S. Geological Survey \\ Mark D. Myers, Director
}

U.S. Geological Survey, Reston, Virginia: 2007

For product and ordering information:

World Wide Web: http://www.usgs.gov/pubprod

Telephone: 1-888-ASK-USGS

For more information on the USGS — the Federal source for science about the Earth,

its natural and living resources, natural hazards, and the environment:

World Wide Web: http://www.usgs.gov

Telephone: 1-888-ASK-USGS

Any use of trade, product, or firm names is for descriptive purposes only and does not imply endorsement by the U.S. Government.

Although this report is in the public domain, permission must be secured from the individual copyright owners to reproduce any copyrighted materials contained within this report.

Suggested citation:

Stephenson, W.J., Williams, R.A., Odum, J.K., and Worley, D.M., 2007, Miscellaneous high-resolution seismic imaging investigations in Salt Lake and Utah Valleys for earthquake hazards: U.S. Geological Survey Open-File Report 2007-1152, 29 p. 


\section{Contents}

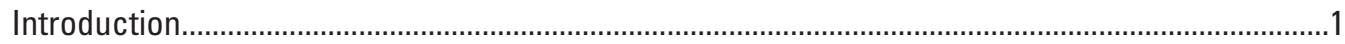

Proof-of-Concept Minivib P-Wave Imaging Profile in South-Central Salt Lake Valley......................1

Deep S-wave Minivib Reflection/Refraction Soundings in Salt Lake and Utah Valleys....................3

Interpretation Methodology .....................................................................................................

Saltair 4

Siesta Drive

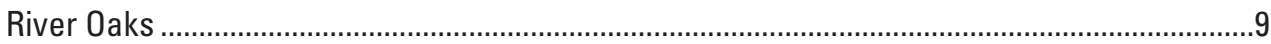

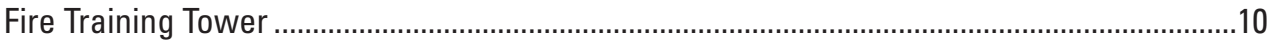

North Oquirrh Mountains ................................................................................................... 10

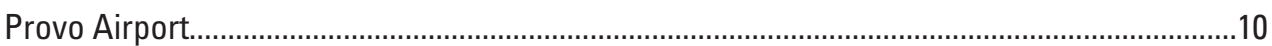

Exchange Park

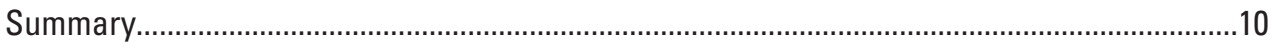

Vs30 (and Vp30) Surface Investigations in Utah Valley................................................................

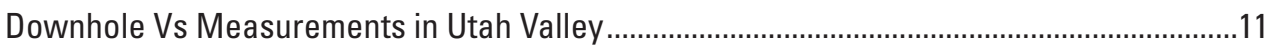

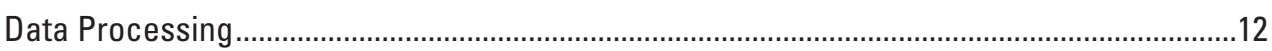

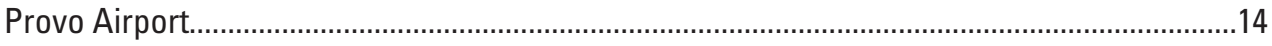

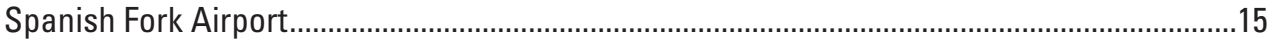

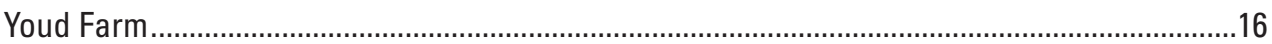

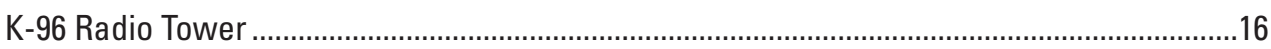

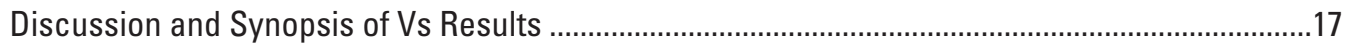

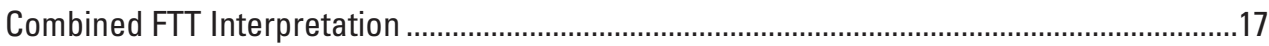

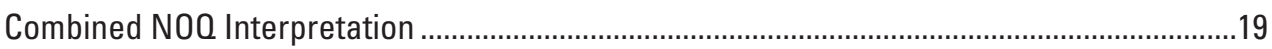

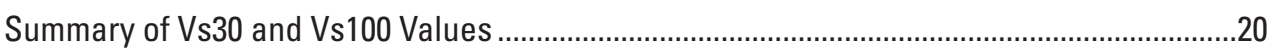

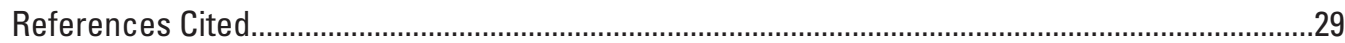

\section{Figures}

1. Investigated sites in Salt Lake and Utah Valleys...........................................................5

2. Line location of minivib P-wave seismic imaging profile along $3200 \mathrm{~W}$. in

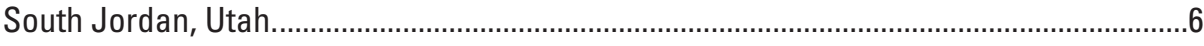

3. Photos of minivib during acquisition along $3200 \mathrm{~W}$. in South Jordan, Utah......................7

4. Typical field records along $3200 \mathrm{~W}$. in South Jordan, Utah ............................................

5. Depth-converted P-wave seismic reflection profiles........................................................8

6. Schematic of general acquisition geometry used at seven minivib

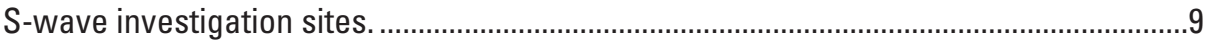

7A. Traces from combined Saltair (SA) minivib S-wave seismic records used for refraction interpretation, sorted by source-sensor offset distance .................................11

7B. Common midpoint (CMP) reflection stack at site SA overlain by "best"

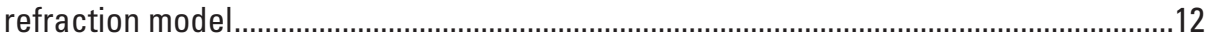

8. Final hybrid S-velocity models for the seven minivib S-wave soundings in Salt Lake and Utah Valleys. 
9A. Traces from combined Siesta Drive (SD) minivib S-wave seismic records used for refraction interpretation sorted by source-sensor offset

9B. CMP reflection stack at site SD overlain by "best" refraction model

10. Traces from two minivib records sorted by offset .

11. Traces from combined fire training tower (FTT) S-wave minivib seismic records used for refraction interpretation sorted by source-sensor offset.

12. (A) Traces from combined S-wave minivib seismic records near Advanced National Seismic System seismograph station NOQ.

(B) NOO refraction picks and results from robust linear least-squares regression analysis

13A. Traces from combined S-wave minivib seismic records at Provo Airport (PA) site sorted by source-sensor offset.

13B. CMP reflection stack at site PA overlain by "best" refraction model

14. Traces from combined Exchange Park (EP) S-wave minivib seismic records used for refraction interpretation, sorted by source-sensor offset

15. Spanish Oaks (SOGC) shear-timber Vs and sledgehammer Vp site

16. Spanish Fork Canyon Elementary School (SFCE) shear-timber Vs and sledgehammer Vp site

17. Spanish Fork Clark Park (SFCP) shear-timber Vs and sledgehammer Vp site .................24

18. Spanish Fork Airport (SFA) shear-timber Vs and sledgehammer Vp site..........................25

19. S-velocity models for the four downhole S-wave soundings in Utah Valley are shown as solid lines on graph .26

20. Fire training tower (FTT) comparison of minivib, shear-timber, and SASW results ........27

21. (A) Shear-timber data acquired at site NOO and interpreted velocity-depth structure. (B) Comparison of minivib and shea

\section{Tables}

1. Geographic locations of study sites and estimated Vs30 and Vs100 values ....................2

2. Processing parameters for P-wave seismic profile in South Jordan, Utah .......................4

3. Generalized processing parameters for S-wave common mid-point (CMP) seismic reflection profiles in Salt Lake and Utah Valleys, Utah. 


\title{
Miscellaneous High-Resolution Seismic Imaging Investigations in Salt Lake and Utah Valleys for Earthquake Hazards
}

\author{
By W.J. Stephenson, R.A. Williams, J.K. Odum, and D.M. Worley
}

\section{Introduction}

In support of earthquake hazards and ground motion studies by researchers at the Utah Geological Survey, University of Utah, Utah State University, Brigham Young University, and San Diego State University, the U.S. Geological Survey Geologic Hazards Team Intermountain West Project conducted three high-resolution seismic imaging investigations along the Wasatch Front between September 2003 and September 2005. These three investigations include: (1) a proof-of-concept $\mathrm{P}$-wave minivib reflection imaging profile in south-central Salt Lake Valley, (2) a series of seven deep (as deep as $400 \mathrm{~m}$ ) S-wave reflection/refraction soundings using an S-wave minivib in both Salt Lake and Utah Valleys, and (3) an S-wave (and P-wave) investigation to $30 \mathrm{~m}$ at four sites in Utah Valley and at two previously investigated S-wave (Vs) minivib sites. In addition, we present results from a previously unpublished downhole S-wave investigation conducted at four sites in Utah Valley.

The locations for each of these investigations are shown in figure 1. Coordinates for the investigation sites are listed in Table 1. With the exception of the P-wave common midpoint (CMP) reflection profile, whose end points are listed, these coordinates are for the midpoint of each velocity sounding. Vs30 and Vs100, also shown in Table 1, are defined as the average shear-wave velocities to depths of 30 and $100 \mathrm{~m}$, respectively, and details of their calculation can be found in Stephenson and others (2005). The information from these studies will be incorporated into components of the urban hazards maps along the Wasatch Front being developed by the U.S. Geological Survey, Utah Geological Survey, and numerous collaborating research institutions.

\section{Proof-of-Concept Minivib P-Wave Imaging Profile in South-Central Salt Lake Valley}

We acquired approximately $2.7 \mathrm{~km}$ of P-wave seismicreflection CMP data along 3200 West in South Jordan, Utah, in the south-central Salt Lake Valley (fig. 2), with a 6,370-kg minivib II source truck. Our goals for this study were to: (1) assess the effectiveness of using the minivib II in an urbanized portion of Salt Lake Valley, and (2) image the R1, R2, and R3 reflectors beneath this section of the valley. These reflectors in the Salt Lake Basin are important seismic boundaries separating unconsolidated and semiconsolidated sediments, semiconsolidated and consolidated sediments, and consolidated sediments and basement rock, respectively, as summarized by Hill and others (1990). In particular, the R2 boundary is believed to be a major earthquake ground motion amplifier within the valley (Olsen and others, 1995).

The profile (fig. 2) was along a north-south arterial roadway with significant automobile traffic. The data were acquired using both a 10-m source and receiver spacing and single $8-\mathrm{Hz}$ vertical geophones. Four 14 -second seismic sweeps between 10 and $200 \mathrm{~Hz}$ were stacked for each source location. We recorded between 72 and 159 channels per field record, dictated by field logistics along the profile, with the majority of records having 120 channels. Photographs of the 6,370-kg minivib II in action along 3200 West are shown in figure 3 . The profile, acquired north-to-south, benefited from a well-maintained grass strip for sensor planting and wide roads for more than one-half of the profile's length. Typical field records from the northern, middle, and southern portions of the profile are shown in figure 4 . The variable number of channels per source point is evident in each of the records. Sourcegenerated surface waves and significant urban noise are also evident throughout these records.

Data processing was conventional, and the processing steps are listed sequentially in table 2. Analyzing the surface waves for S-velocity structure (results not shown) was unsuccessful to depths greater than about $10 \mathrm{~m}$ because of the limited bandwidth governed by both the 10 - to $200-\mathrm{Hz}$ source sweep and 8-Hz sensors. Stacking these data using S-wave velocities was also not successful at delineating S-velocity structure because of the high ambient noise prevalent throughout the records. An interpreted P-wave depth-converted stack and its post-stack migrated counterpart are shown in figure 5 .

We interpret four main reflections beneath the northern end of the profile. Of these, only the shallowest reflection is traceable to the profile's southern end (fig. 5). The three 
Table 1. Geographic locations of study sites and estimated Vs30 and Vs100 values.

\begin{tabular}{|c|c|c|c|c|c|}
\hline Site & Data Type & $\begin{array}{c}\text { Latitude, } \\
\mathbf{N}^{\circ}\end{array}$ & $\begin{array}{c}\text { Longitude, } \\
\text { W }^{\circ}\end{array}$ & $\begin{array}{c}\text { Vs30, Vs100, } \\
\mathrm{m} / \mathrm{s}\end{array}$ & $\begin{array}{l}\text { Surface } \\
\text { Unit** }\end{array}$ \\
\hline $\begin{array}{l}\text { South Jordan (SJ) } \\
\text { profile, north end }\end{array}$ & P-wave CMP & $40.5797^{\dagger}$ & $111.9675^{\dagger}$ & ------- & -------- \\
\hline $\begin{array}{l}\text { South Jordan (SJ) } \\
\text { profile, south end }\end{array}$ & P-wave CMP & $40.5556^{\dagger}$ & $111.9675^{\dagger}$ & ------- & ------- \\
\hline Saltair (SA) & S-wave minivib & 40.82370 & 112.06784 & 180,270 & Q01 \\
\hline Siesta Drive (SD) & S-wave minivib & 40.61099 & 111.83996 & 280,435 & Q02 \\
\hline River Oaks (RO) & S-wave minivib & 40.58449 & 111.91534 & 245,400 & Q02 \\
\hline $\begin{array}{l}\text { Fire Training } \\
\text { Tower (FTT) }\end{array}$ & $\begin{array}{l}\text { S-wave minivib } \\
\text { S-wave timber }\end{array}$ & $\begin{array}{l}40.68656 \\
40.68653\end{array}$ & $\begin{array}{l}112.08576 \\
112.08698\end{array}$ & $\begin{array}{l}480,620 \\
690\end{array}$ & Q03 \\
\hline $\begin{array}{l}\text { North Oquirrh } \\
\text { Mountains (NOQ) }\end{array}$ & $\begin{array}{l}\text { S-wave minivib } \\
\text { S-wave timber }\end{array}$ & $\begin{array}{l}40.6519^{\dagger} \\
40.65270\end{array}$ & $\begin{array}{l}112.1211^{\dagger} \\
112.12080\end{array}$ & $\begin{array}{l}620,1,100 \\
660\end{array}$ & $\mathrm{P}$ \\
\hline $\begin{array}{l}\text { Provo Airport } \\
\text { (PA) }\end{array}$ & S-wave minivib & 40.22649 & 111.71094 & 160,235 & Q01 \\
\hline $\begin{array}{l}\text { Exchange Park, } \\
\text { Provo (EP) }\end{array}$ & S-wave minivib & $40.2475^{\dagger}$ & $111.6711^{\dagger}$ & 190,310 & Q02 \\
\hline $\begin{array}{l}\text { Spanish Oaks Golf } \\
\text { Course (SOGC) }\end{array}$ & S-wave timber & 40.08766 & 111.59842 & 370 & Q03 \\
\hline $\begin{array}{l}\text { Spanish Fork } \\
\text { Airport (SFA) }\end{array}$ & S-wave timber & 40.14518 & 111.67367 & 200 & Q01 \\
\hline $\begin{array}{l}\text { Clark Park, } \\
\text { Spanish Fork } \\
\text { (SFCP) }\end{array}$ & S-wave timber & 40.12281 & 111.64675 & 230 & Q01 \\
\hline $\begin{array}{l}\text { Canyon } \\
\text { Elementary, } \\
\text { Spanish Fork } \\
\text { (SFCE) }\end{array}$ & S-wave timber & 40.09278 & 111.62613 & 350 & Q02 \\
\hline $\begin{array}{l}\text { Provo Airport } \\
\text { (DPA) }\end{array}$ & Downhole & 40.223 & 111.721 & 161 & Q01 \\
\hline $\begin{array}{l}\text { K96 radio tower, } \\
\text { Provo (K96) }\end{array}$ & Downhole & 40.212 & 111.671 & 202 & Q01 \\
\hline $\begin{array}{l}\text { Spanish Fork } \\
\text { Airport (DSFA) }\end{array}$ & Downhole & 40.135 & 111.661 & 223 & Q01 \\
\hline Youd Farm (YF) & Downhole & 40.133 & 111.730 & 223 & Q01 \\
\hline
\end{tabular}

* Mapped surface unit from Solomon and others (2004).

$\dagger$ Coordinates estimated using GoogleEarth ${ }^{\circledR}$.

deeper reflections are probably not traceable across the entire section because of both lower data coverage, caused by acquisition logistics, and higher urban noise caused by heavier automobile traffic as acquisition proceeded south. With only limited information from nearby boreholes that penetrate to these interpreted horizons, we speculate the shallowest and strongest reflection represents the $\mathrm{R} 1$ interface. A borehole near the profile location documents the $\mathrm{R} 1$ reflector at a depth of $98 \mathrm{~m}$ (G. McDonald, Utah Geological Survey, written commun., 2006), which coincides with the approximate depth of the shallowest strong reflector (red horizon in fig. 5); however, previous studies document the R2 as being a higher impedance contrast and therefore a stronger reflection than R1 (Hill and others, 1990; Olsen and others, 1995). By inspection, the 
highest impedance contrast of the depth section would appear to be the red horizon, leaving open the possibility that it may, in fact, be the R2 interface.

If both R1 and R2 are not distinctly imaged in these data, then we suggest several possibilities to explain this observation. It is possible the semi-consolidated sediments between the R1 and $\mathrm{R} 2$ reflectors have either pinched out beneath this portion of the valley, or this sediment package is too thin to be resolved by these data. Alternately, gravity modeling of Radkins (1990) resolved "bedrock," generally correlated with $\mathrm{R} 2$, in the 300-400 $\mathrm{m}$ depth range beneath the seismic profile. A semicontinuous reflector (magenta in fig. 5) does mark a change in reflection character in this depth range, although this reflector is not as laterally coherent as the overlying red horizon. The next most distinct laterally coherent reflector is imaged until a depth of nearly $650 \mathrm{~m}$. This reflector (cyan horizon in fig. 5) may be the R2 reflector, but we consider this scenario as less likely. Finally, a reflector at approximately $900 \mathrm{~m}$ (green horizon in fig. 5) is near the expected depth for the R3 interface based on a recently developed basin model (H. Magistrale, San Diego State University, written commun., 2006).

In summary, the minivib II is a viable source for P-wave acquisition in at least this part of Salt Lake Valley, although future imaging investigations would possibly need to be run at night for less urban noise, with a more powerful source and (or) with multiple source vehicles. Regardless of whether the approximately 100-m-deep high-impedance reflection boundary is R1 or R2, this horizon, gently dipping south, will most likely act as a seismic wave amplifier in the investigated region of the southwestern Salt Lake Valley.

\section{Deep S-wave Minivib Reflection/ Refraction Soundings in Salt Lake and Utah Valleys}

The goal of our second investigation was to obtain Svelocity structure to at least a $100-\mathrm{m}$ depth at selected sites throughout Salt Lake and Utah Valleys using minivib S-wave reflection/refraction data (fig. 1). Because the focus of this investigation was to image as deep as possible with this source, the resulting S-velocity structures represent coarse proxies of the subsurface. The site locations were guided in part by the mapped Quaternary surface geologic units within the valleys: Q01, Q02, and Q03 (finer-to-coarser grain size; for example, Ashand and McDonald,2003; Solomon and others 2004). The minivib I S-wave source, mounted on an identical vehicle but (at $5,194 \mathrm{~kg}$ ) lighter than the P-wave minivib II (fig. 3 ), coupled sufficiently well to asphalt, concrete, and compacted gravel surfaces in this study; however, source coupling undoubtedly introduced noise in some instances in these data.

Data were acquired at seven sites within or along the edge of these urbanized sedimentary basins along the Wasatch Front, with five in Salt Lake Valley and two in Utah Valley.
At each site, a 290-m sensor array was laid out with a source point at each end (fig. 6). Where possible, source points were also positioned every $100 \mathrm{~m}$ out to a $300-\mathrm{m}$ distance from each end of the sensor array. These source points offset the farthest provide redundancy for deeper imaging, but they were not always used in data analysis if the respective 300-m source records had a high signal-to-noise ratio. At four of the sites, where it was logistically practical, intra-array source points (records) were collected for CMP profiling at every second or third sensor location. Sensor stations were spaced $5 \mathrm{~m}$ apart; to enhance signal-to-noise two $4.5-\mathrm{Hz}$ single-component horizontal sensors aligned perpendicular to the line azimuth were summed in series at each location.

\section{Interpretation Methodology}

The first step for refraction analysis was to pick the first arrivals on data based on visual inspection of refraction-phase signal at available offsets. Not all data were incorporated if signal-to-noise was deemed low. Additionally, only the best data trace at a given source-sensor offset was used because offset-stacking tended to distort refraction phases. The firstarrival picks were next assigned to subsurface seismic layers in an initial refraction model based on traveltime-offset analysis. A robust least-squares linear regression algorithm in Matlab ${ }^{\circledR}$ was then used to estimate intercept time and apparent refraction velocity for each picked layer. Finally, these intercept times and apparent velocities were forward-modeled using the refraction code of Mooney (1984) to develop a "best" 1D refraction velocity model at each site.

Reflection analysis was conducted on data at four sites using ProMAX ${ }^{\circledR}$ processing software. Processing of the S-wave field data to derive final stacked sections was conventional and generally followed the steps in table 3. Poststack migration was not attempted on these data because of both high noise levels at later arrival times and the generally flat-lying nature of the imaged strata. The "best" reflection velocity model was derived by first converting the best stacking velocity field to a smoothed interval velocity field using a ProMAX ${ }^{\circledR}$ proprietary algorithm. This interval velocity field was then averaged between strong reflection horizons to get a single velocity for each interpreted layer.

After processing and analyzing the reflection and refraction phases independently as described previously, our interpretation methodology next involved merging the "best" reflection and refraction models into the final velocity model for each site through both inspection and additional iterative modeling. Refraction model results were preferred over those of the reflection model in the shallowest section where reflection velocity control is poorest. Reflection model results were preferred over refraction results at depths greater than $100 \mathrm{~m}$ and in poor refraction signal areas. When the reflection and refraction models differed markedly in regions with good signal for both (layer depths and (or) velocities varied by greater than 10 percent), we iteratively adjusted the reflection and refraction models within the constraints of the data to converge to a final hybrid model. 
Table 2. Processing parameters for P-wave seismic profile in South Jordan, Utah.

\begin{tabular}{|l|l|}
\hline Processing Step & Parameters/comments \\
\hline Data reformat & SEG 2 to Promax ${ }^{\circledR}$ internal format \\
\hline Geometry installation & Associate cartesian coordinates with data \\
\hline Trace editing & Delete bad/unusable data traces \\
\hline Coherent noise attenuation & $\begin{array}{l}\text { Attenuate coherent noise caused by urban } \\
\text { environment }\end{array}$ \\
\hline Surgical mute & Zero amplitudes within the surface wave noise zone \\
\hline Bandpass filter & Zero-phase Ormsby bandpass, 15-200 Hz \\
\hline Automatic gain correction & 400 ms operator length \\
\hline DSN filter & FX-domain signal-to-noise enhancement \\
\hline Elevation statics & Correct for variations in elevation along line \\
\hline Normal moveout correction & $\begin{array}{l}\text { Use best velocity function estimated from constant- } \\
\text { velocity stack analysis }\end{array}$ \\
\hline CMP Stacking & Stack data by common midpoint (CMP) \\
\hline Post-stack coherent noise attenuation & Attenuate additional coherent noise \\
\hline Post-stack migration & Reverse-time TK implementation \\
\hline Predictive deconvolution & Adaptive L2 norm, 40-ms prediction distance \\
\hline Eigenvector filter (migrated data only) & Attenuate migration tails \\
\hline Time-to-depth conversion & Use best-estimate velocity function for conversion \\
\hline
\end{tabular}

Velocity inversions did not appear to be a significant problem in these data, but by incorporating the reflection information with the refraction results, velocity inversion and thin layer errors should be minimized (e.g., Williams and others, 2003). Additional error in the velocity-depth estimates from these minivib S-wave data are primarily from: (1) acquisition geometry error and variations in topography, (2) refraction picking error that can be as much as 15 milliseconds per source-offset distance, (3) root-mean-square misfit error in the refraction velocity analysis, (4) refraction modeling error caused by averaging over a 290-m array, where non-horizontal bedding is represented by a single 1D structure, and (5) reflection-velocity analysis error caused by limited source-array aperture, limited seismic bandwidth, and random noise. These error sources map into time-to-depth conversion error.

\section{Saltair}

The S-wave sounding at Saltair was on the mapped Q01 Quaternary unit (for example, Ashland and McDonald, 2003; Solomon and others, 2004) in Salt Lake Valley, near the location of an industry P-wave profile and several deep boreholes (for example, Hill and others, 1990). The site was generally west of the Salt Lake City Airport in undeveloped ranch land, which gave an excellent opportunity for deep $\mathrm{S}$-wave imaging (SA in fig. 1). Data quality was generally very high, as shown by the interpreted seismic refraction records in figure 7a. First-arrival traveltime picks are shown in red with their assigned refracting layer shown by blue lines on negative-offset traces only. We collected a source-point record at every third station along the sensor array and processed these data following the general procedures detailed in table 3 to obtain the subsurface image in figure $7 \mathrm{~b}$. Subsurface layering is horizontal to sub-horizontal across the reflection depth section. The initial refraction and reflection models are remarkably similar and required little modification to integrate into a hybrid model for the site. We do not believe these data image sufficiently deep for the R1, R2, or R3 boundaries; however, based on correlation with a nearby industry borehole, the R1 boundary may be present at a 150-m depth (Hill and others, 1990). The final velocity model is interpreted to about a 225-m depth, as shown in figure 8. 


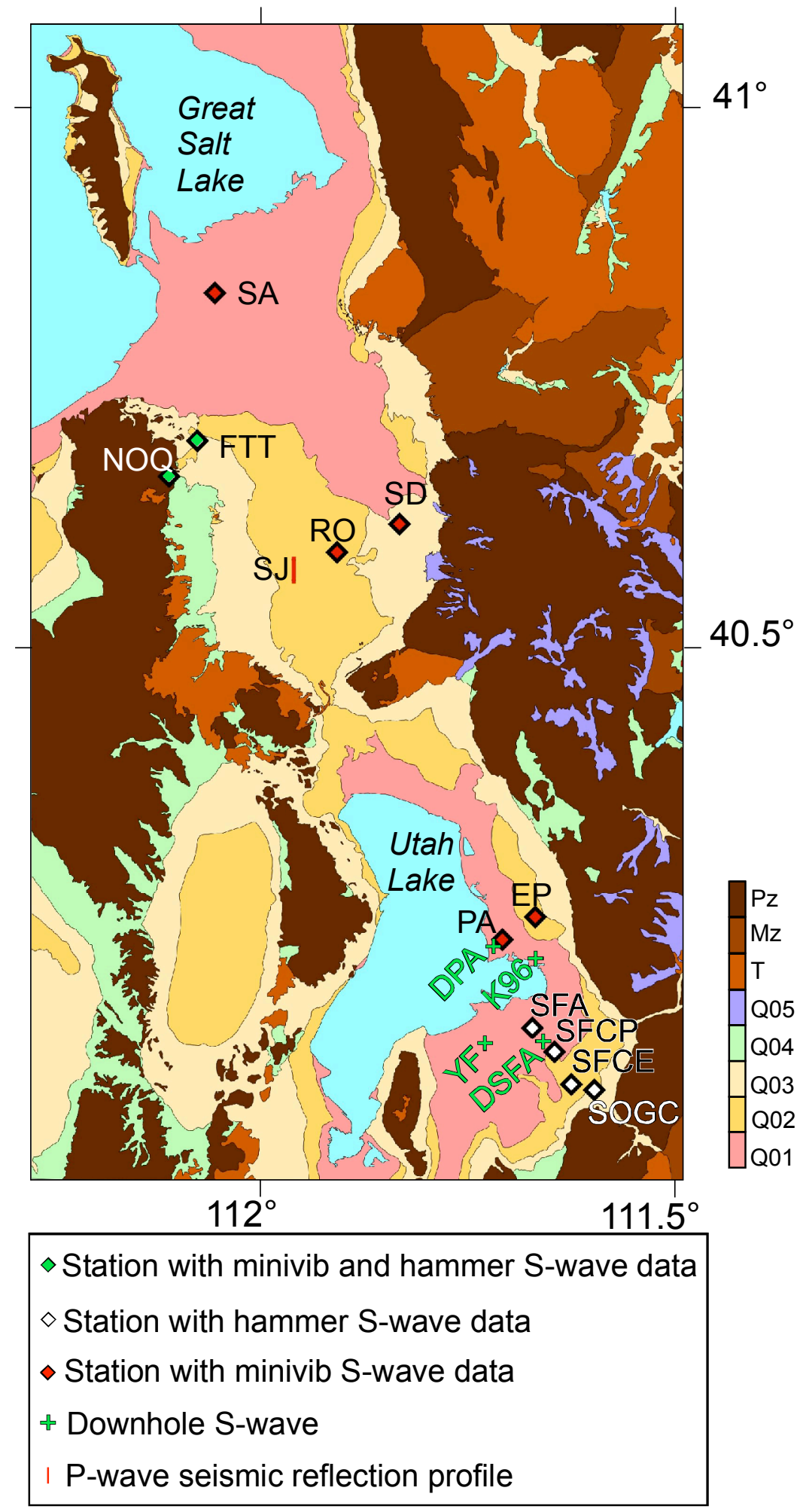

Figure 1. Map of investigated sites in Salt Lake and Utah Valleys. P-wave reflection profile for South Jordan is abbreviated SJ. S-wave minivib sites are SA (Saltair), FTT (Advanced National Seismic System (ANSS) instrument site Fire training tower), RO (River Oaks), SD (Siesta Drive), EP (Exchange Park), PA (Provo Airport), and NOQ (ANSS instrument site). Hammer S- and P-wave sites are SFA (Spanish Fork Airport), SFCP (Spanish Fork Clark Park), SFCE (Spanish Fork Canyon Elementary), SOGC (Spanish Oaks Golf Course), NOQ, and FTT. Downhole sites are DPA (Provo Airport), DSFA (Spanish Fork Airport), YF (Youd Farm), and K96 (K96 radio towers). Map modified from Solomon and others (2004). 


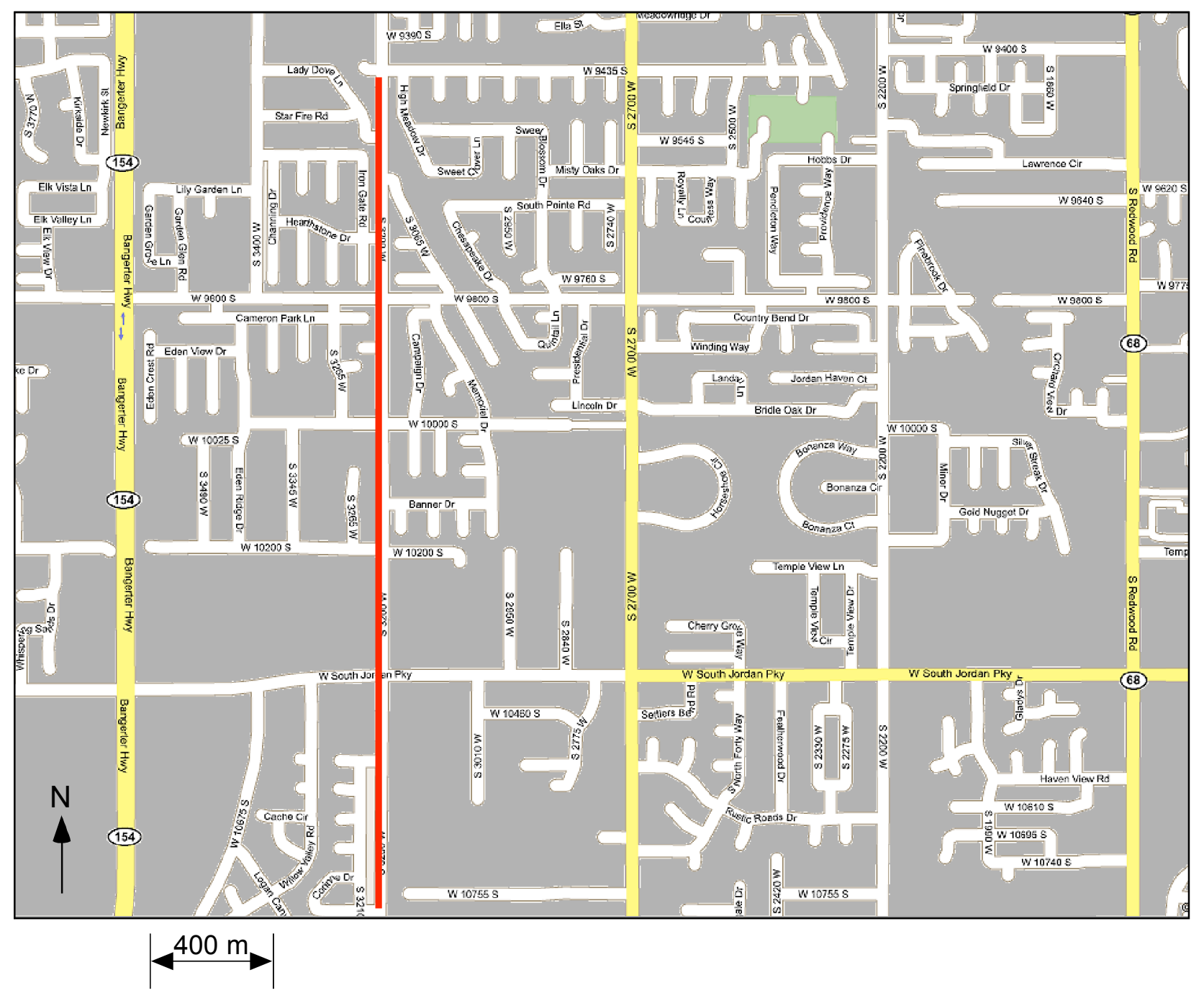

Figure 2. Line location of minivib P-wave seismic imaging profile along $3200 \mathrm{~W}$. in South Jordan, Utah. Profile location shown by red line.

\section{Siesta Drive}

The Siesta Drive sounding (SD, fig. 1) was acquired on the eastern side of Salt Lake Valley on mapped Q02 sediments. Figure 9a shows the interpreted refraction data sorted by source-receiver offset. Data quality is good, although the refraction interpretation is more difficult than at Saltair because of prominent "steps" observed on the first arrivals. These steps suggest a complex wavefield arrival pattern (for example caused by possible velocity inversions, reflected waveforms overprinting refractions, survey geometry). Because the modeling undertaken here cannot accurately handle such complexity, the steps are treated as noise, and picks across them are incorporated into a single layer. These are especially prominent in layer-3 positive-offset picks (inset, fig. 9a). The stacked reflection section shown in figure $9 \mathrm{~b}$ does not support the refraction steps being caused by velocity inversions. The reflection data strongly suggest the presence of two layers between depths of 30 and $100 \mathrm{~m}$ and, given the uncertainties in the refraction interpretation in this depth range due to the "steps," the final model is interpreted as having 5 layers (fig. 8). These data do not image to a depth sufficient for observing the R1, R2, or R3 reflectors. 

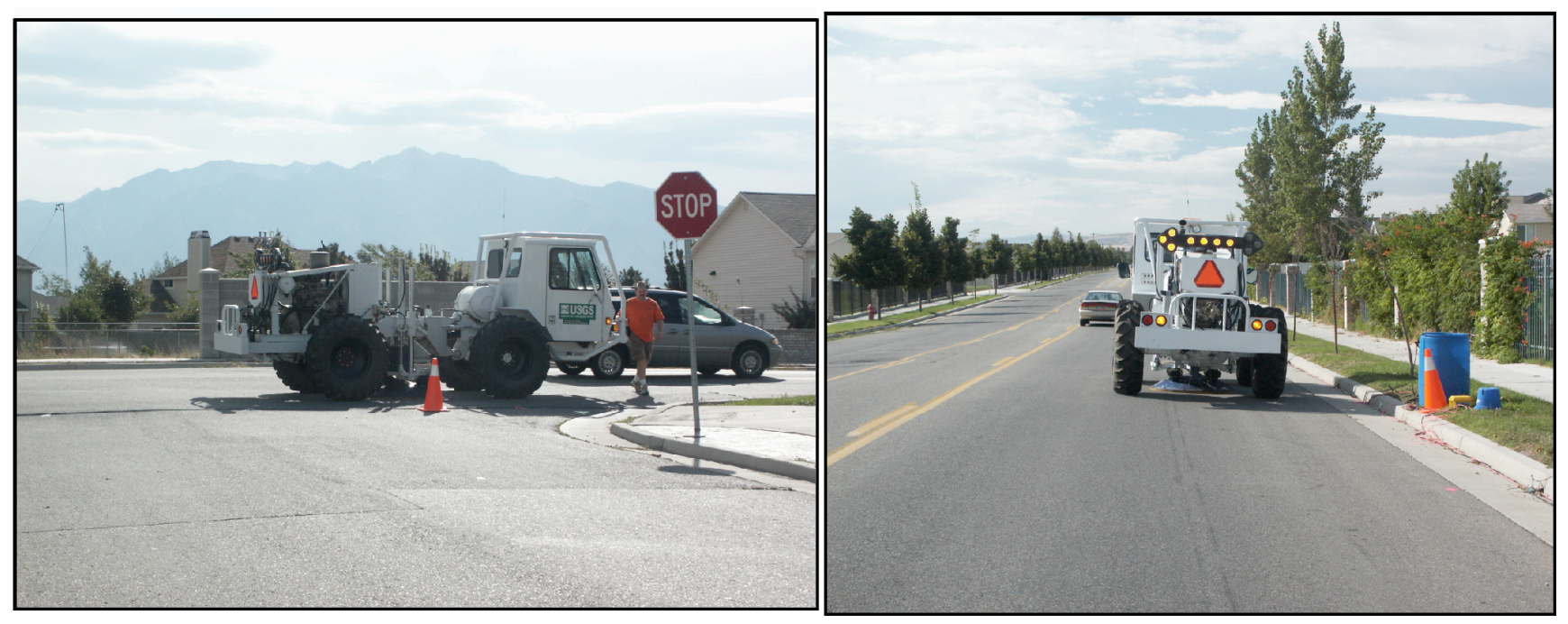

Figure 3. Photos of minivib during acquisition along $3200 \mathrm{~W}$. in South Jordan, Utah. Left: view east toward Wasatch Range; right: view south showing seismic cabling along curb and minivib base plate in contact with asphalt. Similar source vehicle was used during S-wave minivib acquisition in Salt Lake and Utah Valleys during field investigations described in this report.

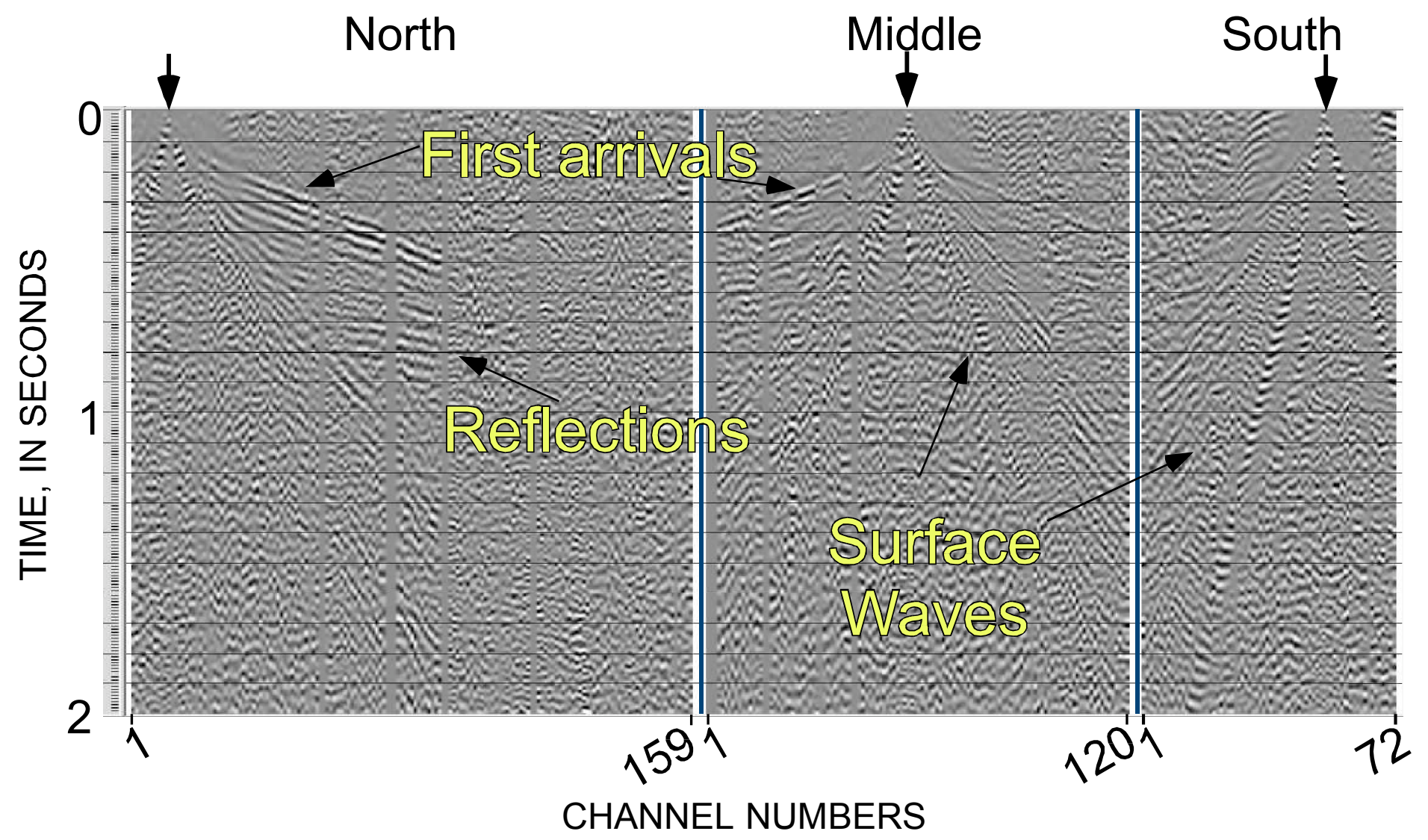

Figure 4. Typical field records along $3200 \mathrm{~W}$. in South Jordan, Utah. Records from northern, middle and southern portion of profile displayed after $400 \mathrm{~ms}$ Automatic Gain Correction and $15-200 \mathrm{~Hz}$ bandpass filter. Arrows indicate location of minivib during acquisition. The effect of urban noise is prevalent throughout records. 

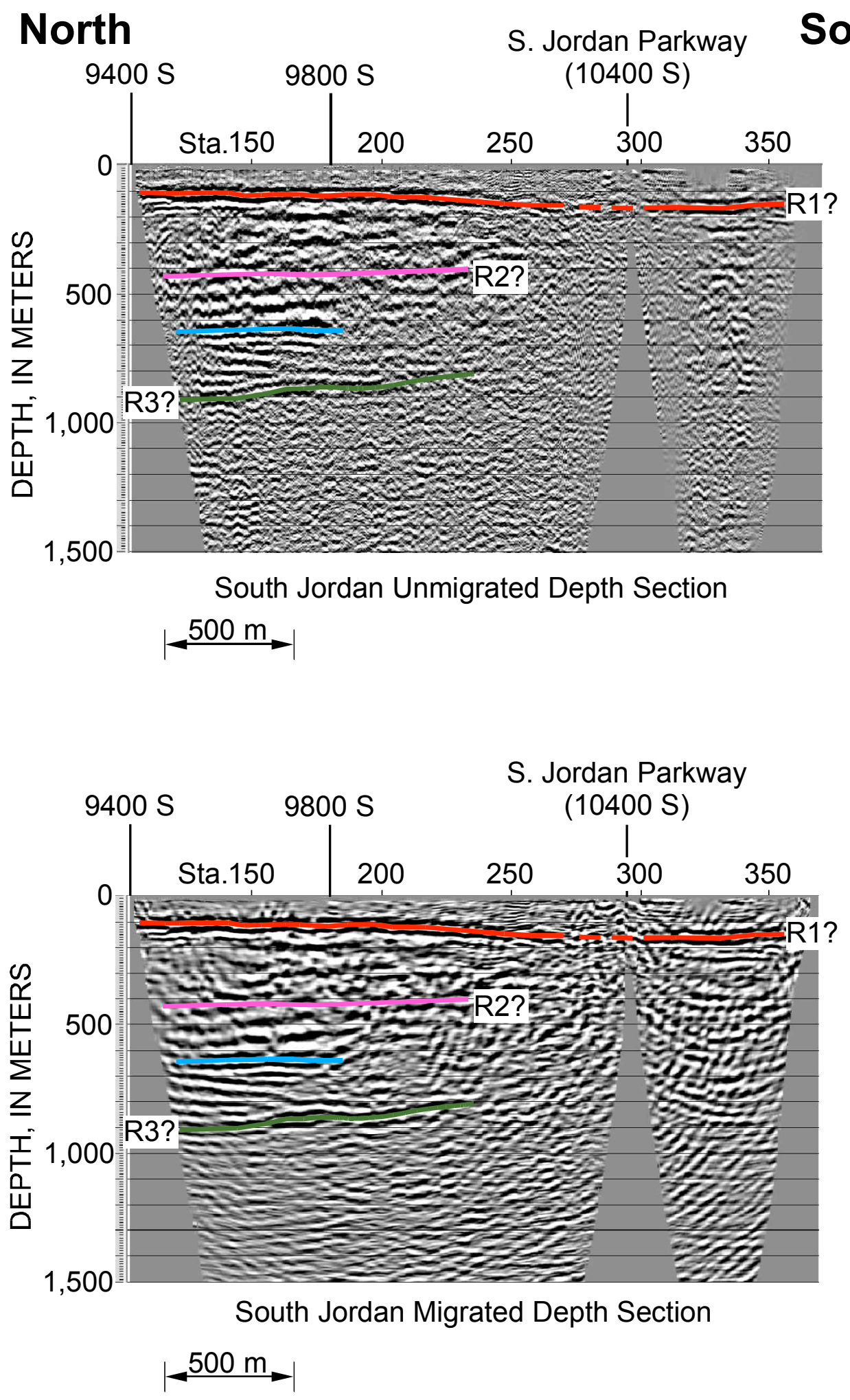

Figure 5. Depth-converted P-wave seismic reflection profiles. Upper: unmigrated; Lower: migrated. Four reflectors (red, magenta, cyan, green) are interpreted on each section. 


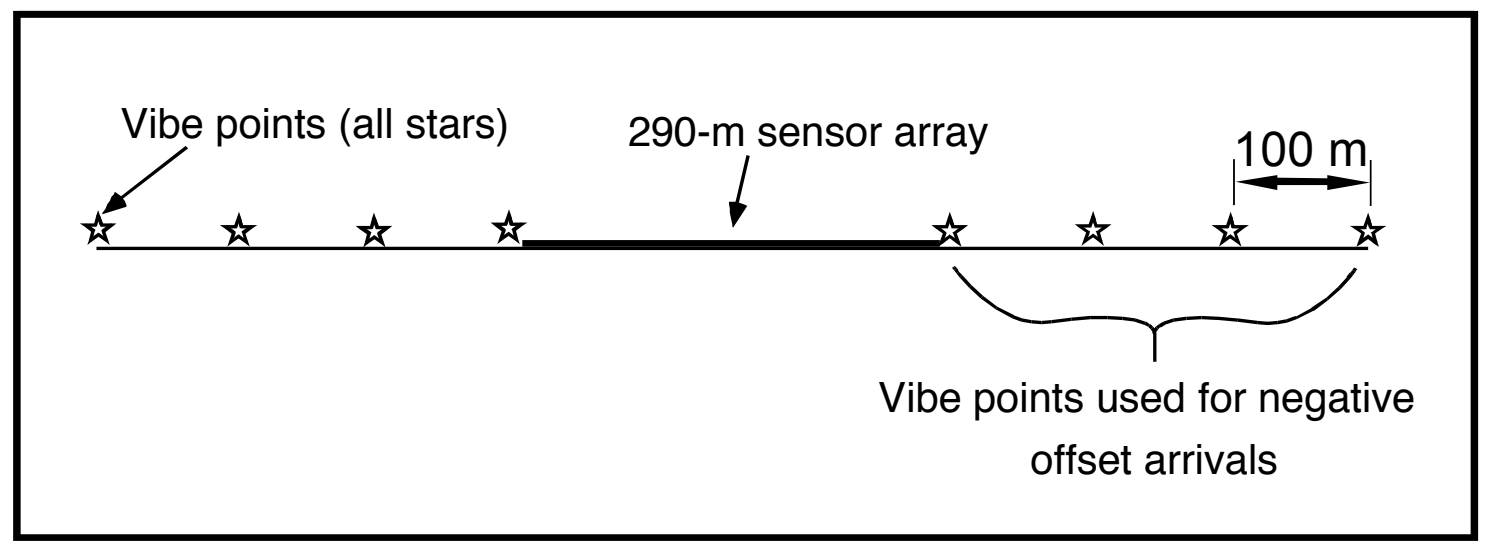

Figure 6. Schematic of general acquisition geometry used at seven minivib S-wave investigation sites. At four of the sites, vibration points were also acquired at every second or third station within the array.

\section{River Oaks}

This S-wave sounding was at the River Oaks Golf Course (RO, fig. 1) on mapped Q02 sediments along the Jordan River. Figure 10 shows the interpreted refraction data sorted by source-receiver offset. Refraction signal quality is lower than for the soundings at Saltair and Siesta Drive. No reflections are clearly evident in these data, as lower-frequency surface waves dominate the records. Limited space prevented reversing the spread at offsets beyond the ends of the sensor array. The refraction picks support a general three-layer interpretation (inset, fig. 10). The final interpreted refraction model is generally faster than either Saltair or Siesta Drive to a 100-m depth (fig. 8). Arnow and others (1970) suggest the depth to $\mathrm{R} 1$ at the River Oaks site is greater that 150-m depth, thus R1 would not be imaged by these $\mathrm{S}$-wave seismic data.

Table 3. Generalized processing parameters for S-wave common mid-point (CMP) seismic reflection profiles in Salt Lake and Utah Valleys, Utah.

\begin{tabular}{|l|l|}
\hline Processing Step & Parameters/comments \\
\hline Data reformat & SEG 2 to ProMAX ${ }^{\circledR}$ internal format \\
\hline Geometry installation & Associate cartesian coordinates with data \\
\hline Trace editing & Delete bad/unusable data traces \\
\hline Bandpass filter & Zero-phase Ormsby bandpass, 5-60 Hz \\
\hline Automatic gain correction & 300 ms operator length \\
\hline Coherent noise attenuation & $\begin{array}{l}\text { Attenuate coherent noise caused by urban } \\
\text { environment using fan filter }\end{array}$ \\
\hline Top mute & Zero amplitudes above direct arrival \\
\hline Elevation statics & Correct for variations in elevation along line \\
\hline Normal moveout correction & $\begin{array}{l}\text { Use best velocity function estimated from constant } \\
\text { velocity stack analysis }\end{array}$ \\
\hline Residual statics & Refine corrections for variations in elevation \\
\hline Dip moveout correction & Prestack partial migration \\
\hline CMP stacking & Stack data by common midpoint \\
\hline Time-to-depth conversion & Use best-estimate velocity function for conversion \\
\hline
\end{tabular}




\section{Fire Training Tower}

The S-wave sounding at the fire training tower was near the Advanced National Seismic System (ANSS) seismograph station FTT on mapped Q03 sediments (fig. 1; in this study, the abbreviation FTT will denote our site, not the ANSS station site). Figure 11 shows the interpreted seismic refraction data, sorted by source-sensor offset. Limited space at the site prevented full reversed-spread refraction shooting at far offsets, akin to River Oaks, thus depth of investigation is less than $100 \mathrm{~m}$. The site appears seismically complex and proved initially difficult both to pick and to interpret. Although we attempted reflection processing at this site with field records recorded with the source at every third sensor, no interpretable reflections emerged and are therefore not presented here. These minivib refraction data required amplitude-squared gain adjustment and no filtering, as opposed to automatic gain correction and bandpass filtering used on all other minivib data sets. The refraction data are most confidently interpreted as a two-layer subsurface, although limited far-offset picks do suggest a third high-velocity layer below a 30-m depth. This third layer, at a depth of about $75 \mathrm{~m}$, is consistent with the R2 layer depth of approximately $70 \mathrm{~m}$ in Radkins (1990).

\section{North Oquirrh Mountains}

This S-wave sounding location, as shown in figure 1, was near ANSS seismograph station NOQ, which is installed on a mapped Paleozoic bedrock outcrop (e.g., Ashland and McDonald, 2003; Solomon and others, 2004). Because the station is at a topographically remote location, we were unable to acquire data directly at the seismograph station with the minivib. Instead, acquisition was along a sinuous dirt road approximately $100 \mathrm{~m}$ downslope of and $30 \mathrm{~m}$ lower than NOQ. Refraction arrival times were significantly complicated by line geometry, topography, and possible heterogeneity in underlying bedrock (fig. 12a). The most conservative interpretation of these data is as a two-layer model, as shown in figure 8 .

\section{Provo Airport}

The minivib S-wave sounding near the Provo Airport (PA, fig. 1) was acquired on the Q01-mapped sediments in Utah Valley. Both refraction and reflection information at this location was among the best acquired of the seven sites. Figure 13a shows the interpreted seismic refraction data, sorted by source-sensor offset. Strong refraction arrivals are visible to about $-600 \mathrm{~m}$ offset, but the shooting geometry is unreversed because of permitting logistics. This record section consists of data from three source locations: from offsets 0 to $290 \mathrm{~m},-295$ to $0 \mathrm{~m}$, and -595 to $-300 \mathrm{~m}$. The pre-refraction noise in these three offset ranges differs markedly and is probably related to source coupling variations.
Reflection imaging was exceptional at this site, allowing the velocity model interpretation to extend to a depth of about $420 \mathrm{~m}$. Reflections and reverberations are visible throughout much of the field data (fig. 13a). The combined reflection and refraction "best" models are shown in figure 13b. The top of refraction-model layer 4 (Vs of about $340 \mathrm{~m} / \mathrm{s}$ ) correlates with a reflection at a depth of about $55 \mathrm{~m}$. The final hybrid model for the Provo Airport data is shown in figure 8. This site has the lowest S-velocity structure (130-340 m/s) in the upper 100 $\mathrm{m}$ of any of the investigated minivib sites.

\section{Exchange Park}

Exchange Park (EP, fig. 1) was the second minivib Swave site acquired in Utah Valley and is within the city limits of Provo on mapped Q02 sediments. Refraction arrivals are generally clear in these data, and reflections are also visible (fig. 14). Field logistics allowed a fully reversed refraction acquisition geometry to an almost $600-\mathrm{m}$ offset. This aperture permitted modeling of as many as five layers during refraction analysis (see inset, fig. 14). Reflections were not stacked into a depth section but did provide control on the final velocity model, shown in figure 8 .

\section{Summary}

The minivib S-wave source successfully generated sufficient energy to obtain S-velocity structure images to depths of more than $200 \mathrm{~m}$ at several of the sites along the Wasatch Front. A more robust solution was determined by combining independent reflection and refraction interpretations. These interpreted velocity-depth models should be considered a coarse representation of Vs at each investigated site, with 2-m vertical resolution on average at the 20-m depth and 6-m vertical resolution on average at the 100-m depth.

\section{Vs30 (and Vp30) Surface Investigations in Utah Valley}

We acquired shallow seismic Vs30 (and Vp30) data at four sites in southern Utah Valley along a transect from highest (Q03) to lowest (Q01) S-wave velocity lacustrine deposits mapped at the surface (fig. 1). In addition, we occupied locations near ANSS stations NOQ and FTT because of uncertainty in the earlier interpretations from the minivib S-wave studies done near these sites. Both P- and S-wave reflection/ refraction data were acquired at all six sites, although in this report we emphasize the S-wave results. The source for these data was a sledgehammer impacted on either a shear-timber (S-wave) or a metal plate on the ground (P-wave). Interpretation of these data also utilized the refraction modeling code of Mooney (1984) and incorporated reflection information. The $\mathrm{Matlab}^{\circledR}$ robust linear regression algorithm was not used in the analysis of the refraction picks for these data. 


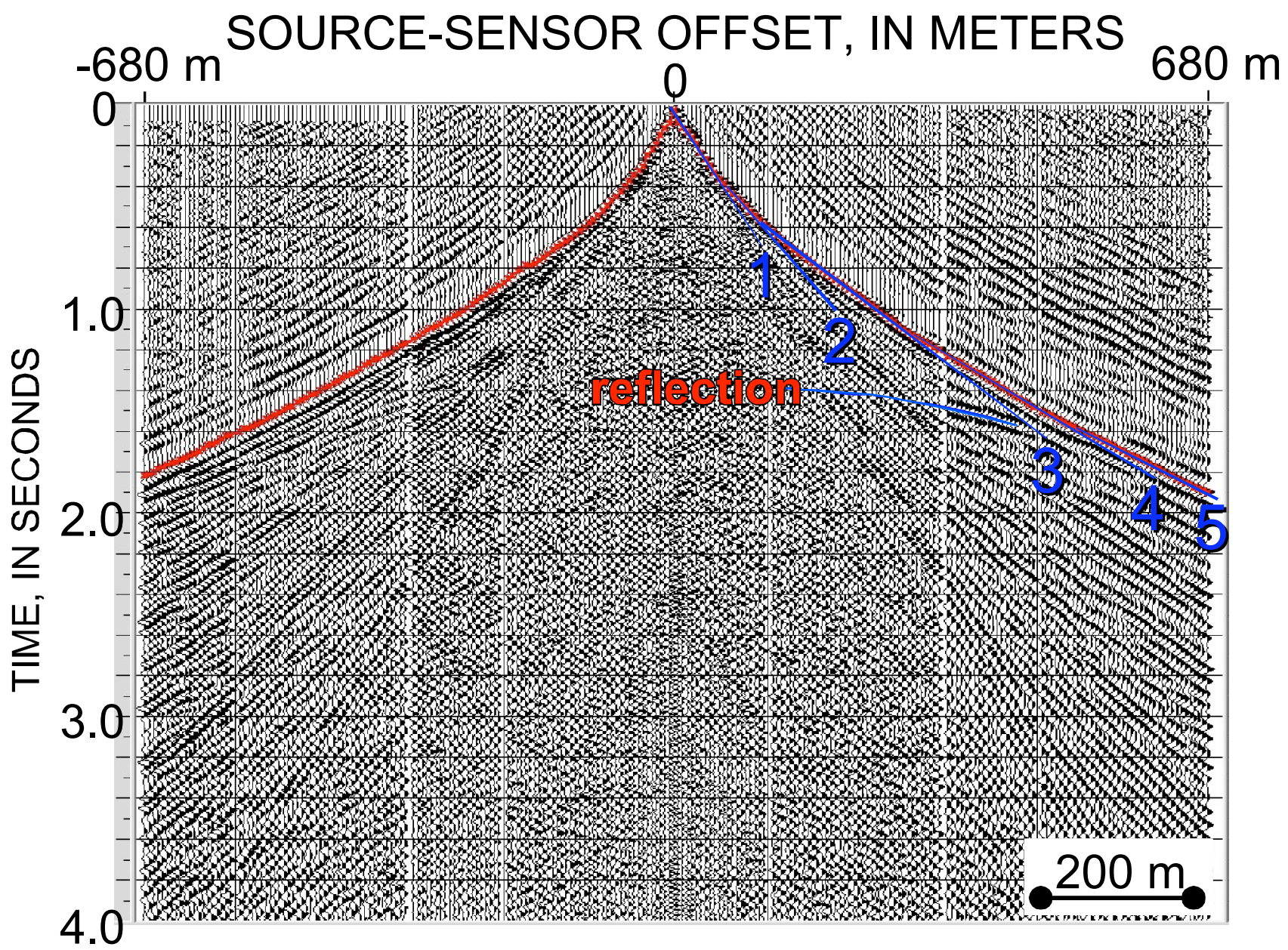

Figure 7 (A). Traces from combined Saltair (SA) minivib S-wave seismic records used for refraction interpretation, sorted by source-sensor offset distance. Refraction picks (red lines) and 5-layer interpretation (blue lines) are shown. Reflection labeled at $1.4 \mathrm{~s}$. Processing on refraction records included geometric sorting of selected records, gain correction (AGC), and bandpass filter $5-60 \mathrm{~Hz}$.

The four Vs30 and Vp30 sites acquired with a sledgehammer source in Utah Valley are presented in figures 15 to 18. Data acquired at each of these sites were of very good quality, lending confidence to the interpreted results. A representative S-velocity record, a table of Vs and Vp models, and a graphical presentation of $\mathrm{Vs}$ and $\mathrm{Vp}$ are shown for each site in each of the respective figures 15 to 18. Data acquired near Spanish Oaks Golf Course (SOGC, figs. 1, 15) are on mapped Q03 deposits, although this site will likely be changed to Q02 in future updated maps (G. McDonald, Utah Geological Survey, written commun., 2006); those acquired near Spanish Fork Canyon Elementary (SFCE, figs. 1, 16) were on mapped Q02 deposits. Progressing northwestward, data acquired near both Clark Park (SFCP, figs. 1, 17) and the Spanish Fork Airport (SFA, figs. 1, 18) were on mapped Q01 deposits. The Vs30 values for these shear-timber sites are listed in Table 1.

\section{Downhole Vs Measurements in Utah Valley}

This section presents previously unpublished borehole data acquired in Utah Valley as part of the investigation presented in Tinsley and others (1991). We have been unable to recover lithologic logs for these boreholes. The borehole acquisition equipment used in this investigation consisted of a portable digital seismograph and a single downhole geophone. The shear-wave seismic source, which was offset about 1.8 $\mathrm{m}$ from the borehole, was a sledgehammer and shear-timber device similar to the "horizontal traction" source described by Kobayashi (1959). The S-wave polarity reversal produced with this method facilitates identification of the shear-wave onset. The start signal, generated by the hammer impact against the timber, served as the origin time. The timing for the source pulse origin time varies slightly (probably less than $0.001 \mathrm{~s}$ ) 


\section{Saltair Reflection Section and Refraction Model}

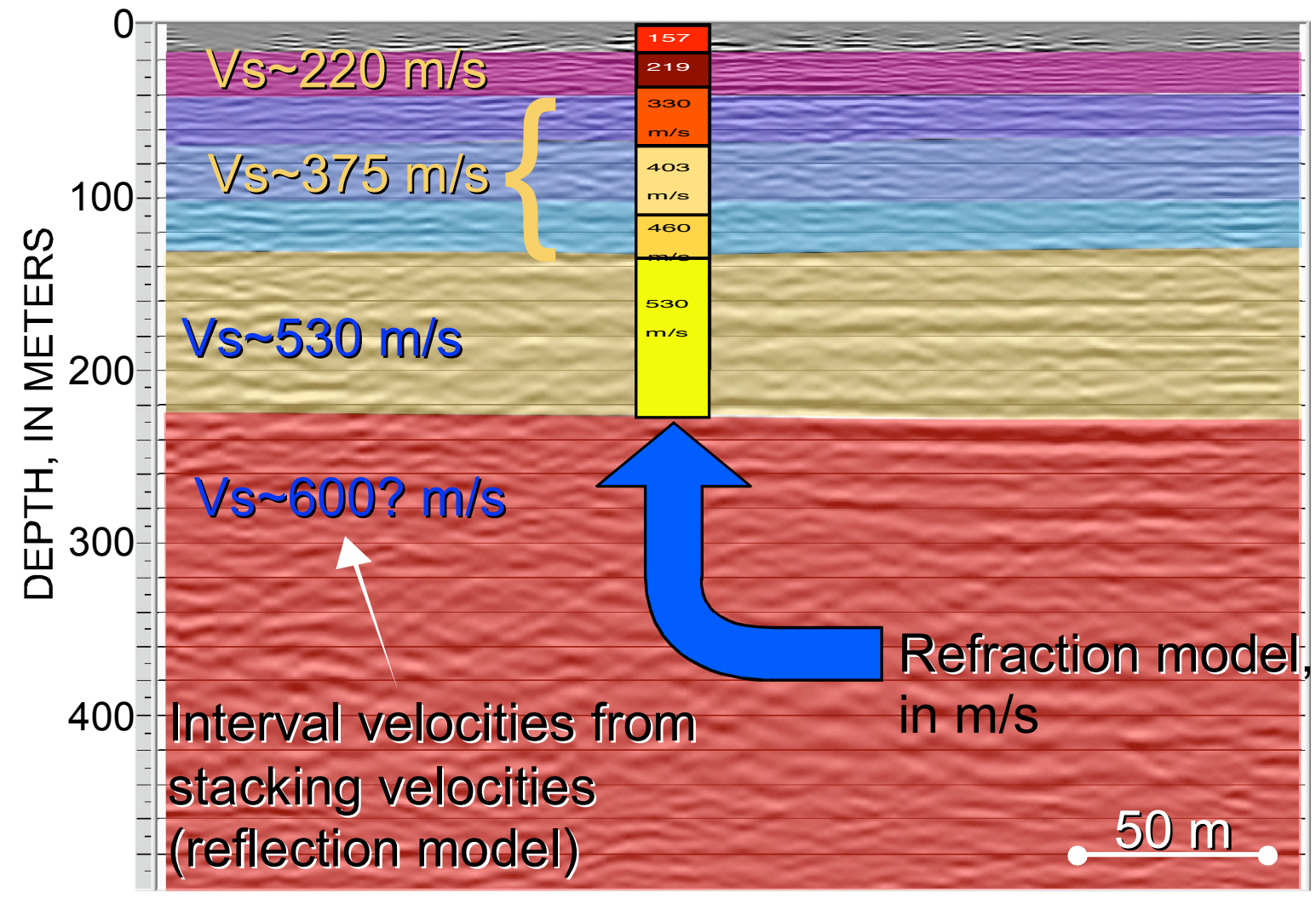

Figure 7 (B). Common midpoint (CMP) reflection stack at site SA overlain by "best" refraction model. Colored areas on both reflection and refraction interpretations represent geologic layers.

due to variable delays in the trigger switch and instrument response. We assume that there will be a reasonably constant time delay in the data that does not significantly affect the derived velocities.

The 15.2-cm diameter boreholes were cased with $10.2-\mathrm{cm}$ diameter plastic pipe and grouted in place. The boreholes were sampled at 2-m vertical intervals using a three-component $28-\mathrm{Hz}$ resonant-frequency geophone. A magnetic declinometer on the geophone was used to orient the geophone at each new depth so that the horizontal S-wave (SH) component was aligned with the shear timber. Because it was difficult to achieve the same orientation at each depth, especially below $30 \mathrm{~m}$, there was a variation of about $\pm 5^{\circ}$ in the $\mathrm{SH}$ component orientation in some cases. This variation in geophone orientation relative to the SH source may account for some of the small arrival time and amplitude differences observed in the data.

\section{Data Processing}

A $180^{\circ}$ wavelet phase reversal identifies the S-wave onset time recorded at each depth. Depending on the record signal quality and the timing scale, time-pick accuracy varies from about 0.001 to $0.003 \mathrm{~s}$ for $\mathrm{S}$ waves. Greater errors in picking wavelet first arrivals occurred on records from greater borehole depths for several reasons: (1) these signals are longer in duration and required a coarser digital time-sampling interval to fit them in the limited seismograph memory space, (2) signal-to-noise ratios tended to decrease with depth, making it sometimes difficult to select the SH-wave first arrival, or (3) some boreholes may have sections of the casing that are poorly coupled to the borehole wall, which could create anomalously low signal amplitude or spurious signals. The greatest impediment to accurate first arrival picks was caused by seismic noise (possibly tube waves) arriving before and 


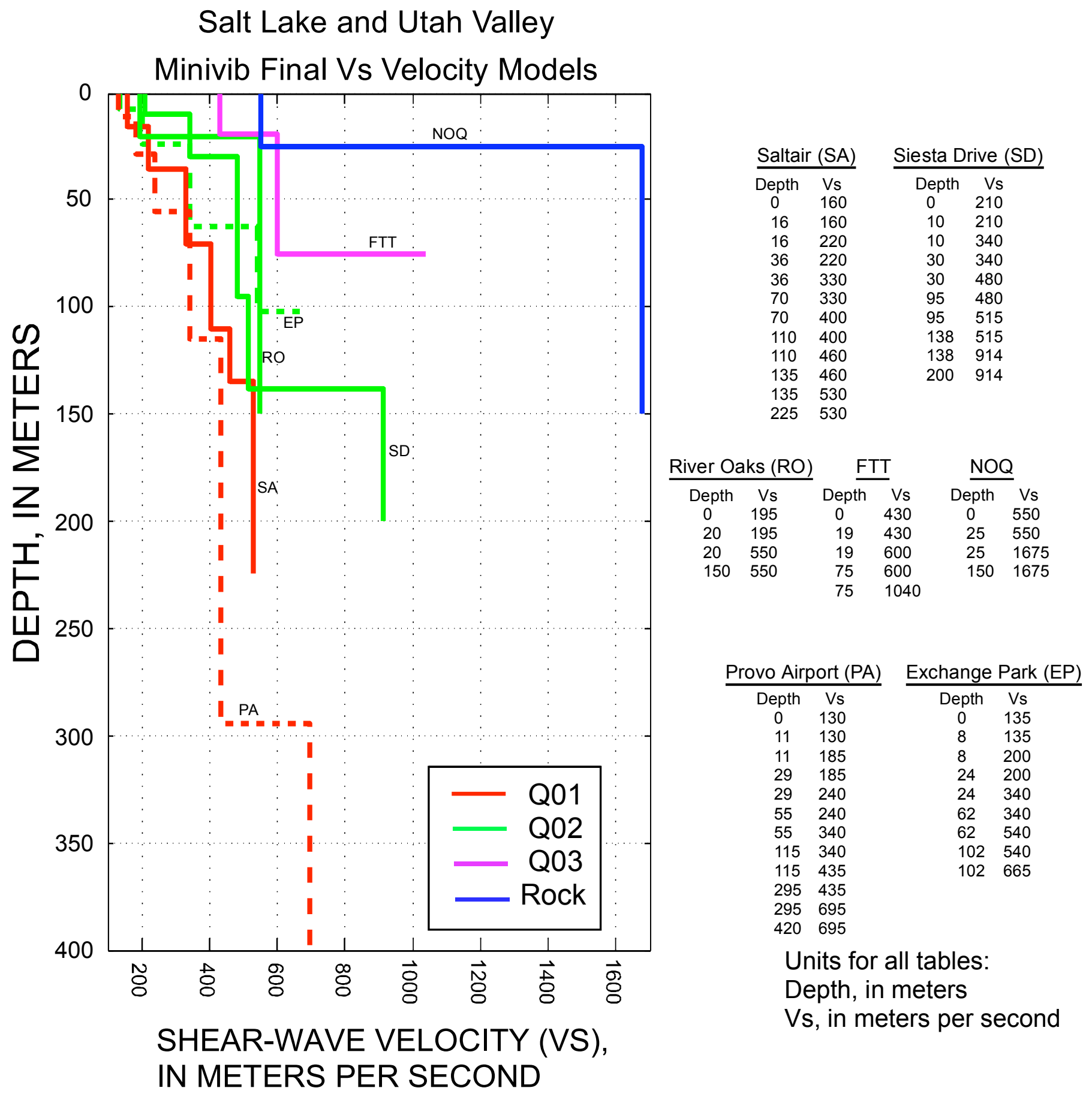

Figure 8. Final hybrid S-velocity models for the seven minivib S-wave soundings in Salt Lake and Utah Valleys. Red lines represent soundings on 001 deposits, green lines are for soundings on 002, magenta lines are for soundings on 003, and blue lines are for sounding on "bedrock" at site NOO. Solid lines represent soundings in Salt Lake Valley while dashed lines represent soundings in Utah Valley. Velocity-depth models in table form are listed to right of diagram. 


\section{SOURCE-SENSOR OFFSET, IN METERS}

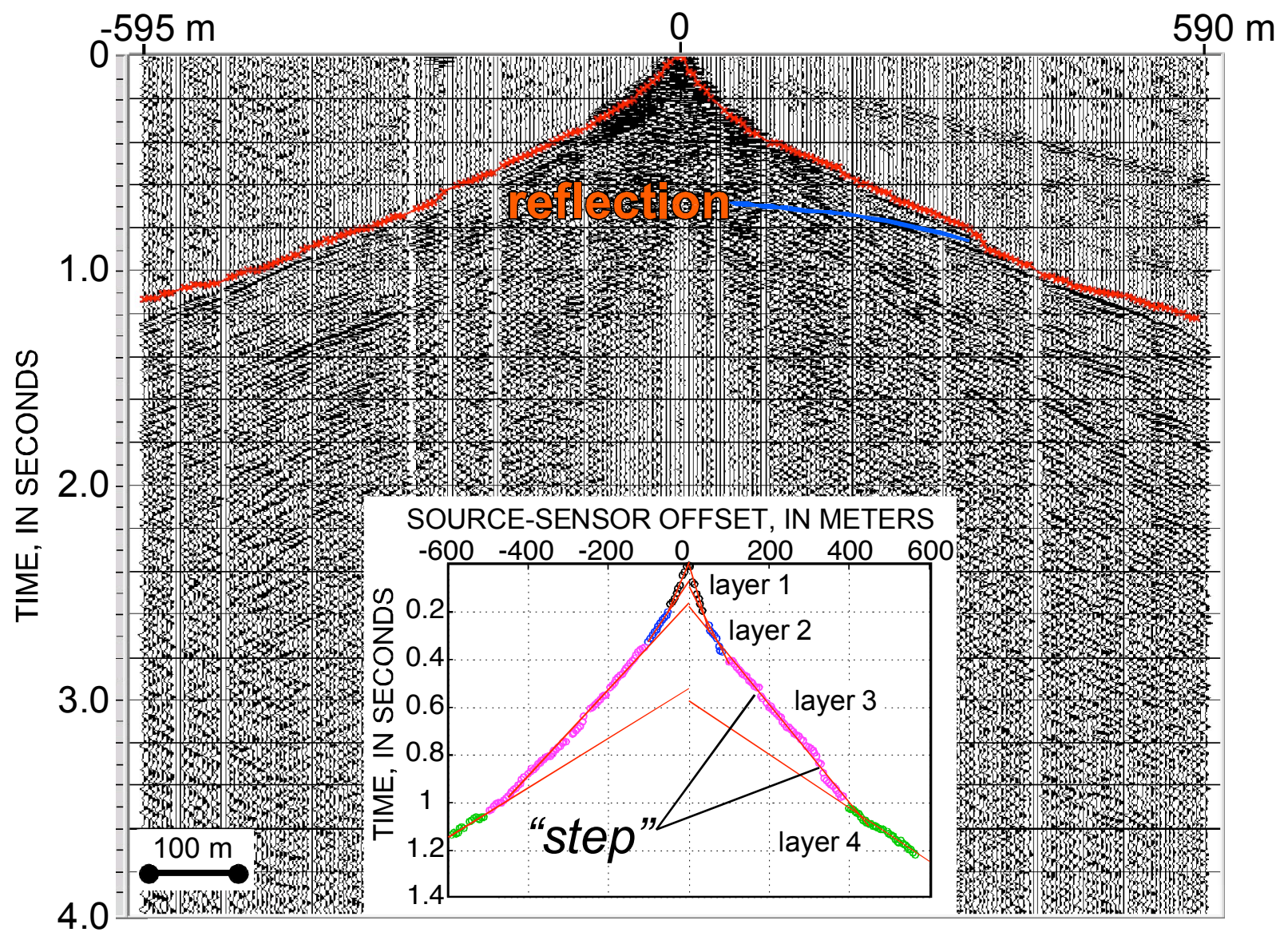

Figure 9 (A). Traces from combined Siesta Drive (SD) minivib S-wave seismic records used for refraction interpretation sorted by source-sensor offset. Refraction picks are shown as red lines and reflection is labeled at about 0.65 seconds. Processing on refraction records included geometric sorting of selected records, gain correction (AGC), and bandpass filter $5-60 \mathrm{~Hz}$. Inset: results of 4-layer interpretation showing picks used for the linear regression as black (layer 1), blue (layer 2), magenta (layer 3), and green (layer 4) circles.

simultaneously with the SH arrival. Usually this noise could be separated from the SH-wave arrival through a comparison of amplitude and polarity; in most cases, the noise was of lower amplitude and did not exhibit a polarity reversal. This report's second author (R.A. Williams) independently analyzed these downhole data.

Intervals of constant seismic velocity within the borehole were determined by visual inspection of the time-depth plots (not shown). Depth intervals on the time-depth plot where consecutive data points display a relatively constant slope (fit by a linear least-squares method) define a constant-velocity interval in a manner similar to the refraction analysis described previously. In all borehole data the linear fits have correlation coefficients of 0.98 to 0.99 .

\section{Provo Airport}

The S-wave downhole data from Provo Airport (DPA, fig. 1), which is located about $1 \mathrm{~km}$ southwest of the Provo Airport S-wave minivib site PA (fig. 1), are quite similar to the minivib data from the 0 to $28-\mathrm{m}$ depth (the maximum downhole data reading) as shown in figure 19 . In the layer from 0 to $11 \mathrm{~m}$, there is a $20 \mathrm{~m} / \mathrm{s} \mathrm{S}$-velocity difference (150 to 130 $\mathrm{m} / \mathrm{s}$ ) between the two sites, and in the layer from 14 to $28 \mathrm{~m}$ the results are essentially identical at about $185 \mathrm{~m} / \mathrm{s}$. These two sites are located on the Q01 Salt Lake Valley equivalent unit. The geologic log from the downhole site indicates that the depth interval from 0 to $28 \mathrm{~m}$ consists mostly of very soft clay in the upper $11 \mathrm{~m}$ (J. Tinsley, U.S. Geological Survey, 


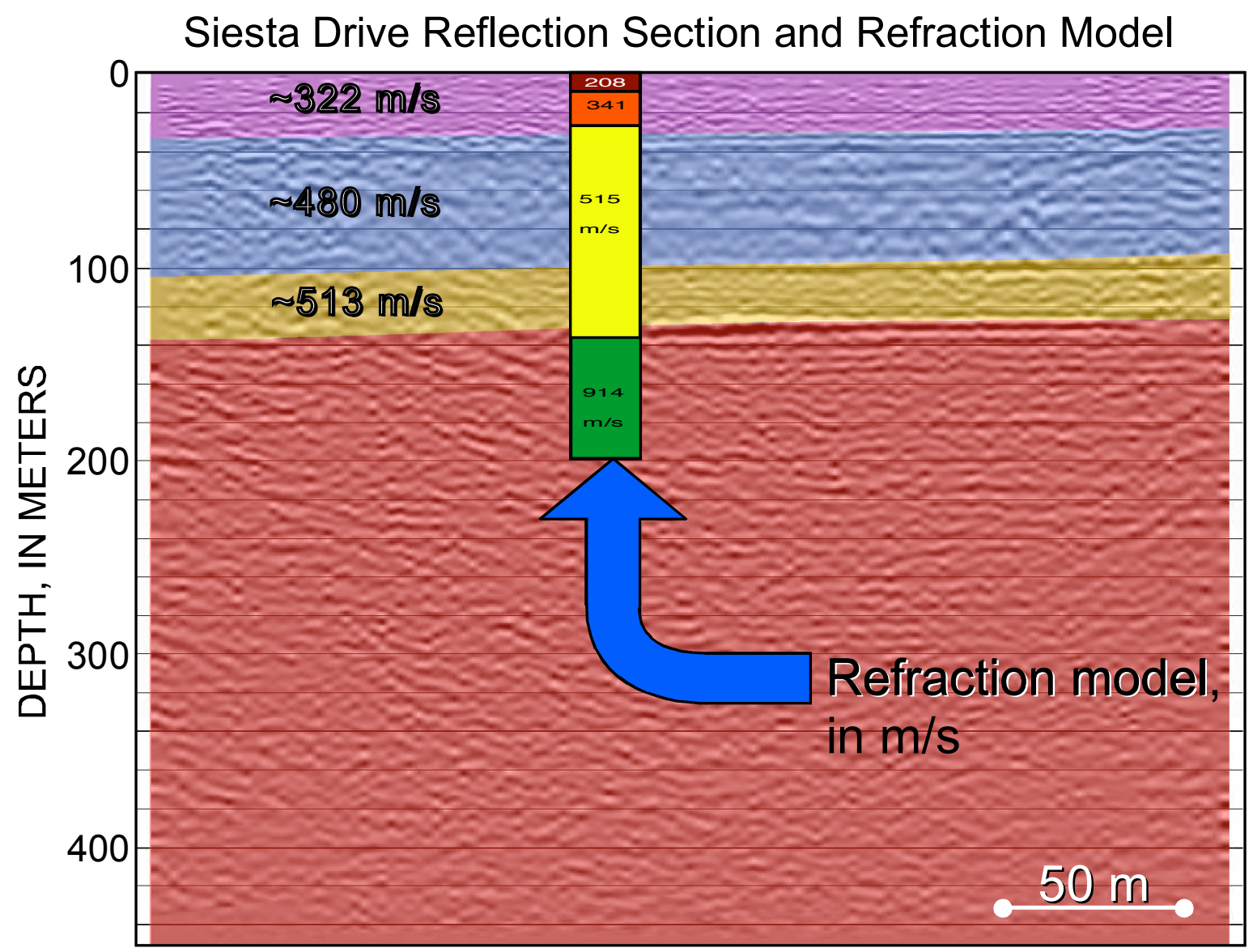

Figure 9 (B). CMP reflection stack at site SD overlain by “best” refraction model.

written commun., 1986). An increase in sand content at about $11 \mathrm{~m}$ appears to be the cause of the jump in Vs from about 130 $\mathrm{m} / \mathrm{s}$ to $185 \mathrm{~m} / \mathrm{s}$. Note that the Vs30 value in table 1 assumes a constant Vs between the last measurement point at $28 \mathrm{~m}$ and the 30-m depth.

\section{Spanish Fork Airport}

In the vicinity of the Spanish Fork Airport (DSFA, fig. 1), we find some differences between the S-wave downhole data and the S-wave hammer refraction/reflection survey in the upper $55 \mathrm{~m}$. The hammer and downhole data sites, which are separated by about $1.5 \mathrm{~km}$, have similar low velocities in the upper $10 \mathrm{~m}$, ranging from 80 to $210 \mathrm{~m} / \mathrm{s}$ (fig. 19). The geologic log from the borehole indicates a change from soft clayey silt to sand at a 4-m depth, which corresponds to the jump from 114 to $212 \mathrm{~m} / \mathrm{s}$ in the downhole data (J. Tinsley, U.S. Geological Survey, written commun., 1986). Another change in Vs occurs at a 10-m depth where the deposits change from sand to stiffer clay. Below about $10 \mathrm{~m}$, however, the downhole record shows three velocity inversions in the 10- to 50-m depth range that are not observed in the refraction/reflection profile. In this depth interval, the downhole Vs oscillates between about 220 and $320 \mathrm{~m} / \mathrm{s}$ while the refraction/reflection data interpretation for this interval is a constant $370 \mathrm{~m} / \mathrm{s}$. Though it was not recognized in the original refraction data interpretation, there is evidence for the presence of at least one low velocity zone below an 11-m depth in the form of a time delay or step in the refraction first arrivals. 


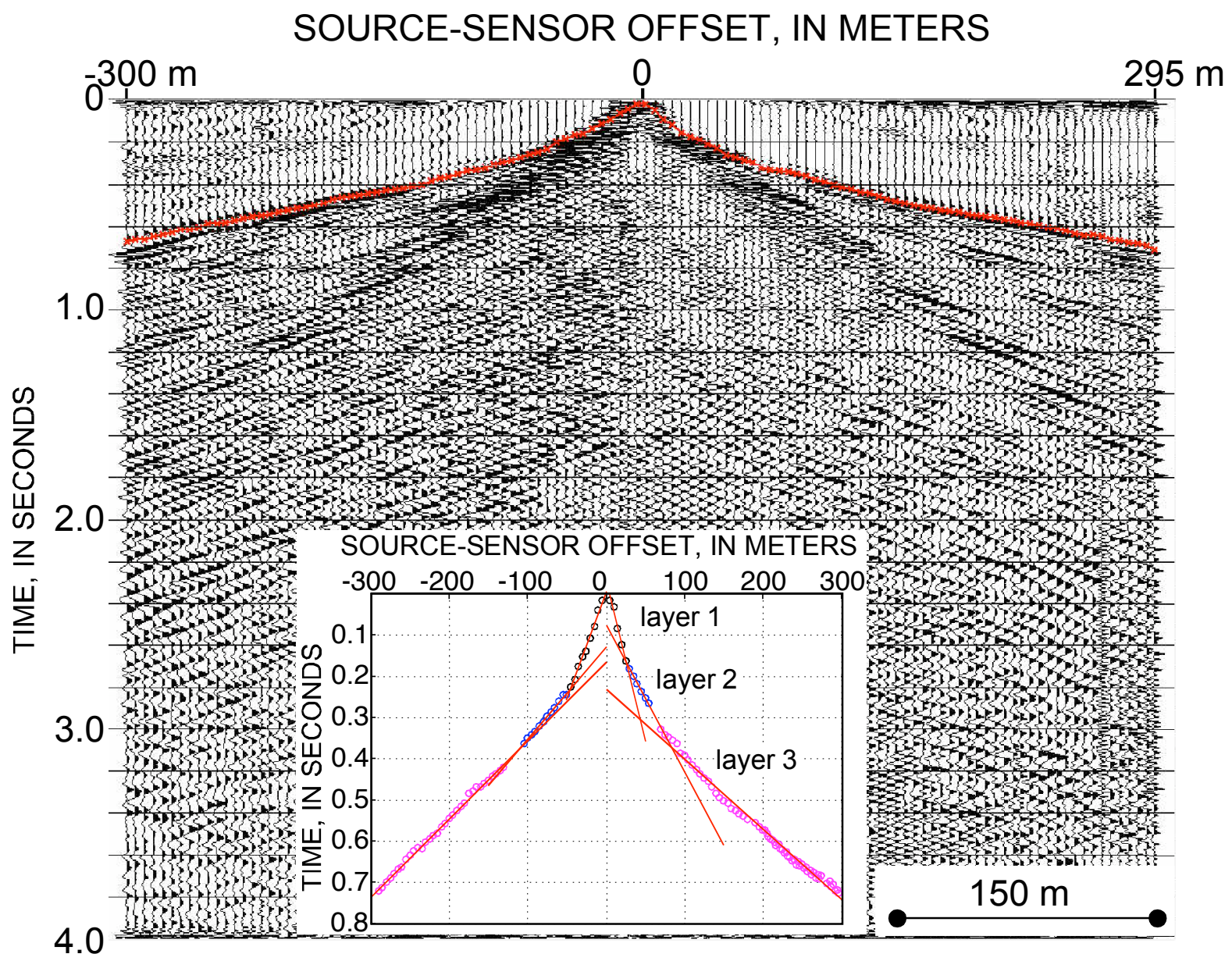

Figure 10. Traces from two minivib records sorted by offset (no room for additional farther-offset minivib source points) at River Oaks (RO) S-wave site. Refraction picks shown as red lines; no reflections are clearly evident in field records. Inset: results of 3-layer interpretation showing first-arrival picks used for the linear regression as black (layer 1), blue (layer 2), and magenta (layer 3) circles.

\section{Youd Farm}

The downhole data at Youd Farm (YF, fig. 1) reveal another soft soil site with S-velocity in the range of 230 to 325 $\mathrm{m} / \mathrm{s}$ to a depth of almost $60 \mathrm{~m}$. The Vs 30 at this site is $231 \mathrm{~m} / \mathrm{s}$ and the Vs66 (bottom of the hole) is $279 \mathrm{~m} / \mathrm{s}$. In contrast to the downhole data at the Provo and Spanish Fork airports, no velocity inversions were interpreted. The Vs maximum of 390 $\mathrm{m} / \mathrm{s}$ is reached at $58 \mathrm{~m}$ and extends to at least the bottom of the hole at a 66-m depth.

\section{K-96 Radio Tower}

This site (K96, fig. 1), which is located near Interstate 15 about $4 \mathrm{~km}$ east-southeast of the Provo Airport downhole site, also has a Vs structure that is characteristic of soft sediments. The downhole data reach a 46-m depth with an average Vs to that depth of only $217 \mathrm{~m} / \mathrm{s}$, which is not much of a change from the Vs30 for this site $(202 \mathrm{~m} / \mathrm{s})$. The Vs maximum is $297 \mathrm{~m} / \mathrm{s}$, which is detected in the 40- to 46-m depth range (fig. 19). 


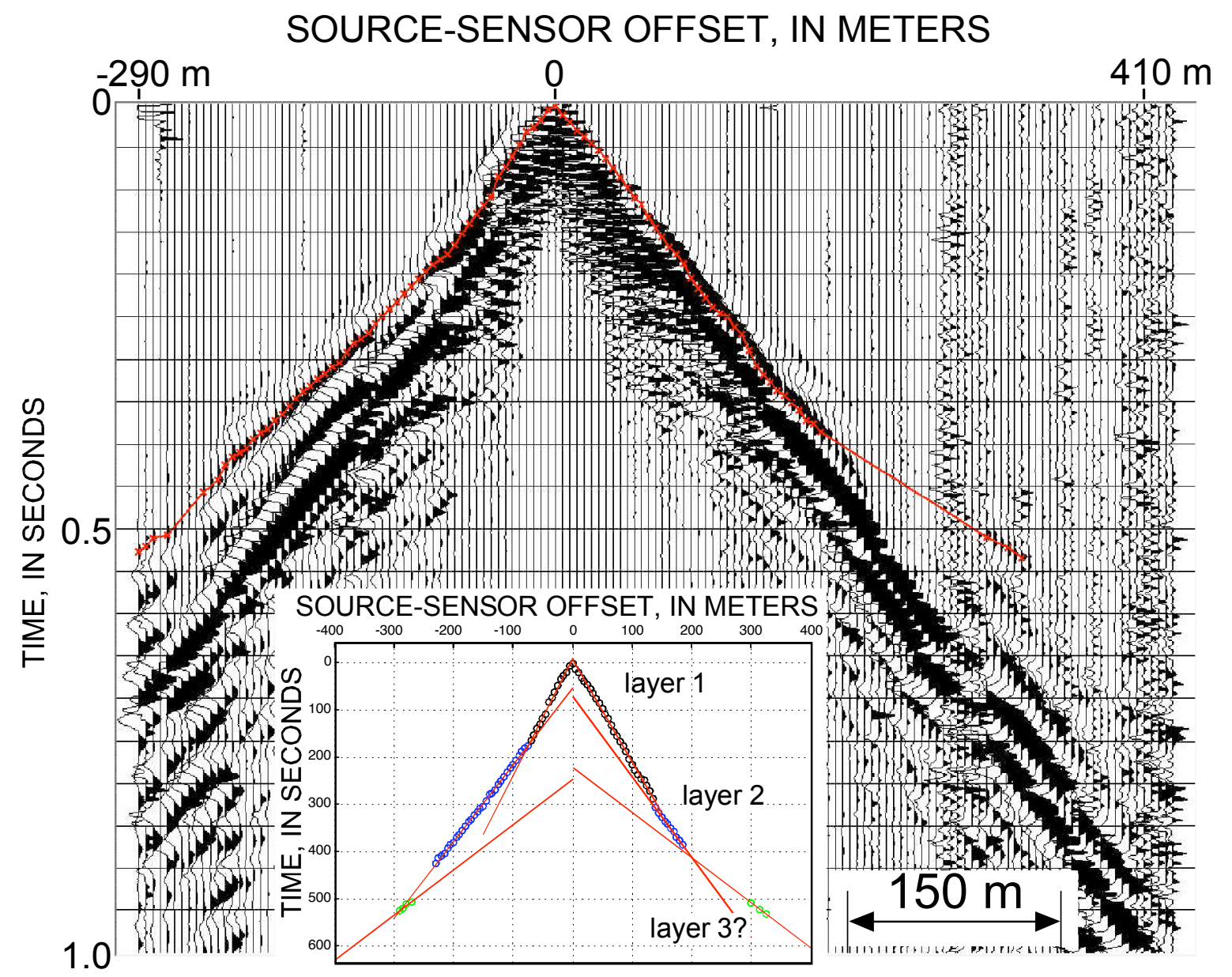

Figure 11. Traces from combined fire training tower (FTT) S-wave minivib seismic records used for refraction interpretation sorted by source-sensor offset. Refraction picks shown as red lines; no reflections are clearly evident in field records. Low refraction signal return (weak arrivals) was probably caused by poor source/ receiver coupling and (or) complex near-surface geologic conditions. Results at this site from the minivib data are problematic. See text for discussion. Inset: results of 3-layer interpretation showing first-arrival picks used for the linear regression as black (layer 1), blue (layer 2), and green (layer 3) circles.

\section{Discussion and Synopsis of Vs Results}

\section{Combined FTT Interpretation}

Because the minivib S-velocity data at FTT were complex and an initial interpretation attempt yielded ambiguous results, shear-timber data were acquired in 2005 to better characterize the shallow subsurface and constrain the minivib interpretation. The shear-timber and the minivib data were not acquired at the exact same location. The minivib array location was based on road access and the need for $290 \mathrm{~m}$ of array distance. The shear-timber array location was established the following year along a portion of the minivib array; however, interim land reworking at the investigated site forced the later shear-timber array center to be offset from the minivib array center. The sensor array locations overlapped but their midpoints are separated by about $100 \mathrm{~m}$ (fig. 20a).
Spectral Analysis of Surface Wave (SASW) data were acquired at two sites near FTT (J. Berry, Utah State University, written commun., 2006). Results from the second acquisition study (SASW2) are shown in figure 20b (analysis by J. Berry and J. Bay, Utah State University, written commun., 2006). The site SASW1 Vs30 result was $422 \mathrm{~m} / \mathrm{s}$ versus the SASW2 result of $432 \mathrm{~m} / \mathrm{s}$, and both velocity-depth models are comparable (J. Berry, Utah State University, written commun., 2006). The SASW2 array center is approximately $250 \mathrm{~m}$ east of the shear-timber array center and about $150 \mathrm{~m}$ east of the minivib center. Because of the minivib array length, the SASW2 array midpoint is roughly on the eastern end of the minivib array. The SASW2 model velocities are consistently lower in the upper $10 \mathrm{~m}$ than either the shear-timber or minivib models.

With higher velocity layers (greater than $500 \mathrm{~m} / \mathrm{s}$ ) getting deeper as the array centers progress eastward, one possibility for the differences between the three models is that bedrock 

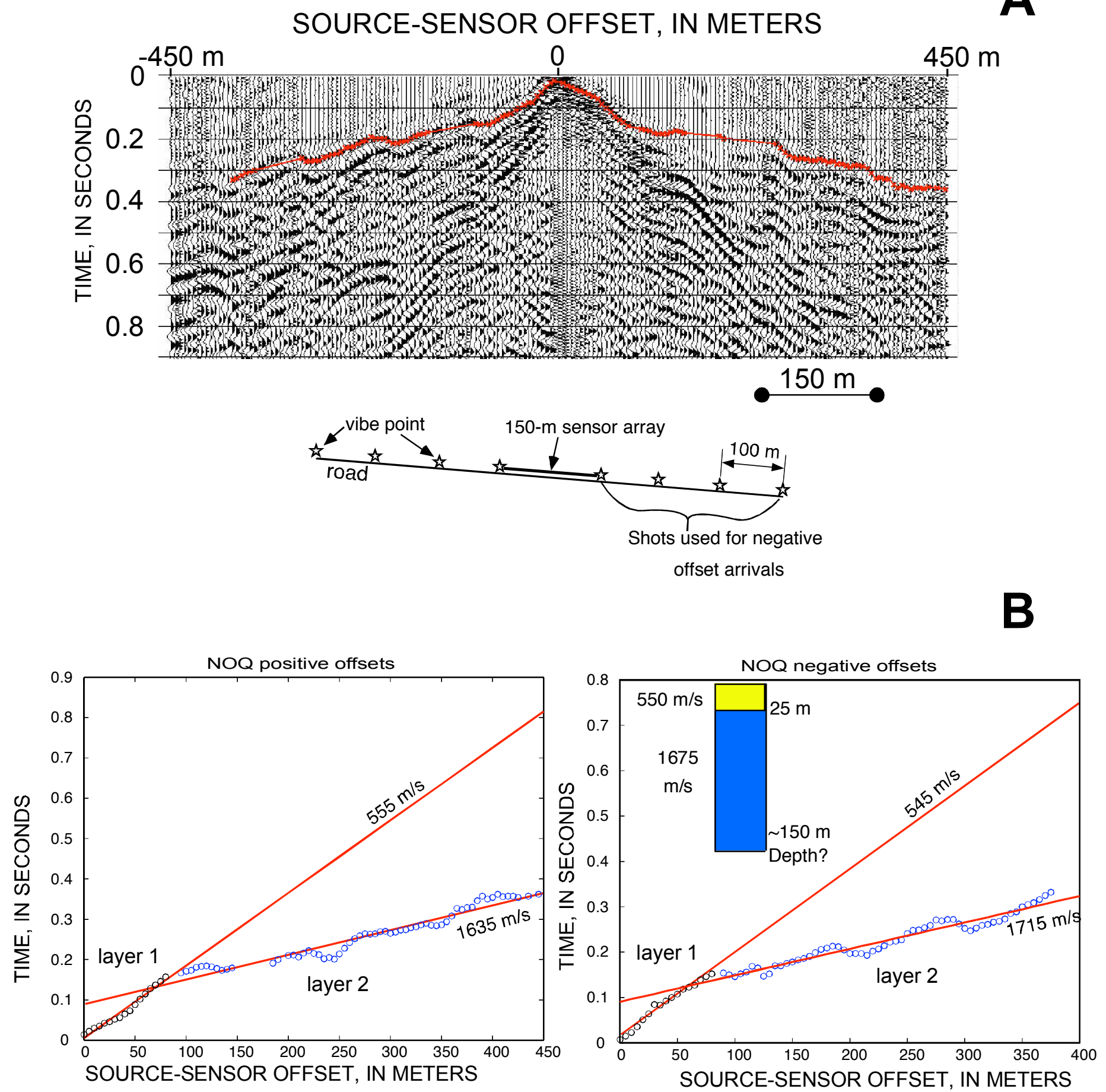

Figure 12. (A) Traces from combined S-wave minivib seismic records near Advanced National Seismic System seismograph station NOO used for refraction interpretation sorted by source-sensor offset. Refraction picks shown as red lines; no reflections observed. Inset: schematic diagram of source-sensor acquisition geometry used to obtain these data about $150 \mathrm{~m}$ south of NOQ along curvy dirt road. The very complex first-arrival pattern is caused in part by acquisition geometry along the narrow dirt road. (B) NOQ refraction picks and results from robust linear least-squares regression analysis. Inset: yellow and blue areas are velocity model derived from regression. 


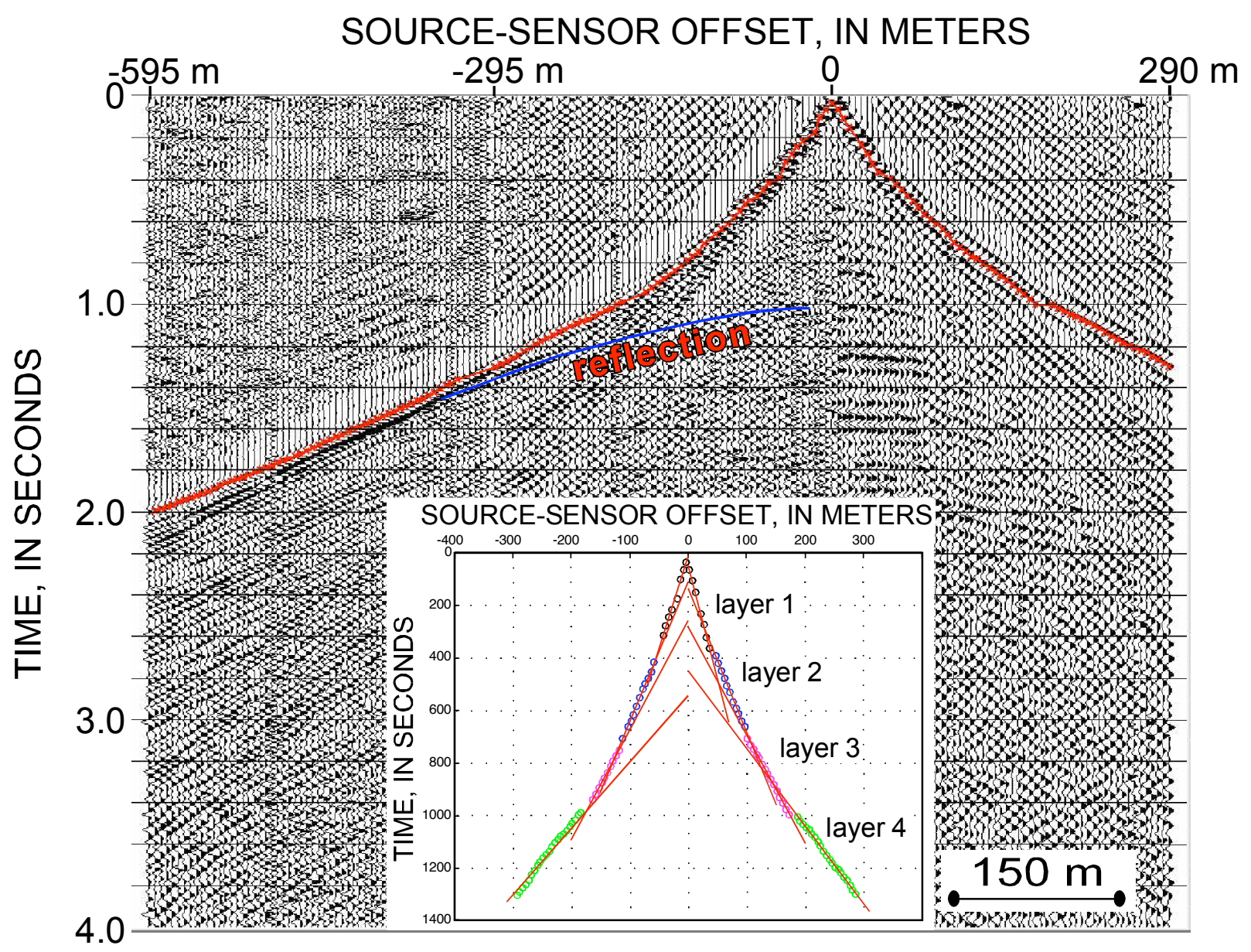

Figure 13 (A). Traces from combined S-wave minivib seismic records at Provo Airport (PA) site sorted by sourcesensor offset. Refraction picks shown by red lines. Reflections and reverberations are visible throughout record section. Refraction arrivals are visible to an offset of about $-600 \mathrm{~m}$, but the profile is unreversed because of permitting logistics. Inset: results of 4-layer interpretation showing first-arrival picks used for the linear regression as black (layer 1), blue (layer 2), magenta (layer 3), and green (layer 4) circles.

complexity such as a dipping sediment-bedrock contact is being mapped by the different methods. Depending on how layers are correlated between the S-timb, SASW2, and S-vibe results shown in figure $20 \mathrm{~b}$, bedrock or high-velocity soil layers would only need to dip $5^{\circ}-30^{\circ}$ east in plane-dipping scenario. Within the uncertainties of these acquisition methods, the minivib and SASW results are consistent in the upper $30 \mathrm{~m}$ near the FTT station location, as evidenced by the Vs30 values of $480 \mathrm{~m} / \mathrm{s}$ and $432 \mathrm{~m} / \mathrm{s}$, respectively. Additionally, assuming the interface at about $13 \mathrm{~m}$ depth in the shear-timber result is the base of the soil column, the Vs13 for this site is about $481 \mathrm{~m} / \mathrm{s}$ as well (as noted by G. McDonald, Utah Geological Survey, written commun., 2006).

\section{Combined NOQ Interpretation}

Shear-timber data were acquired within several meters of ANSS seismograph station NOQ, crossing from limestone outcrop onto an inferred thin veneer of alluvium/colluvium. These shear-timber data are very high quality, as demonstrated by the clean first breaks in the reverse-polarity plot in figure 21a. These data suggest layer boundaries at 10 and $17 \mathrm{~m}$. The minivib Vs 30 value of $620 \mathrm{~m} / \mathrm{s}$ is lower than the sheartimber Vs30 of $660 \mathrm{~m} / \mathrm{s}$, which is not surprising given that the minivib acquisition was along a gravel road near the stream channel, with presumably more alluvial cover and weathered material than at station NOQ, while the shear-timber data were 


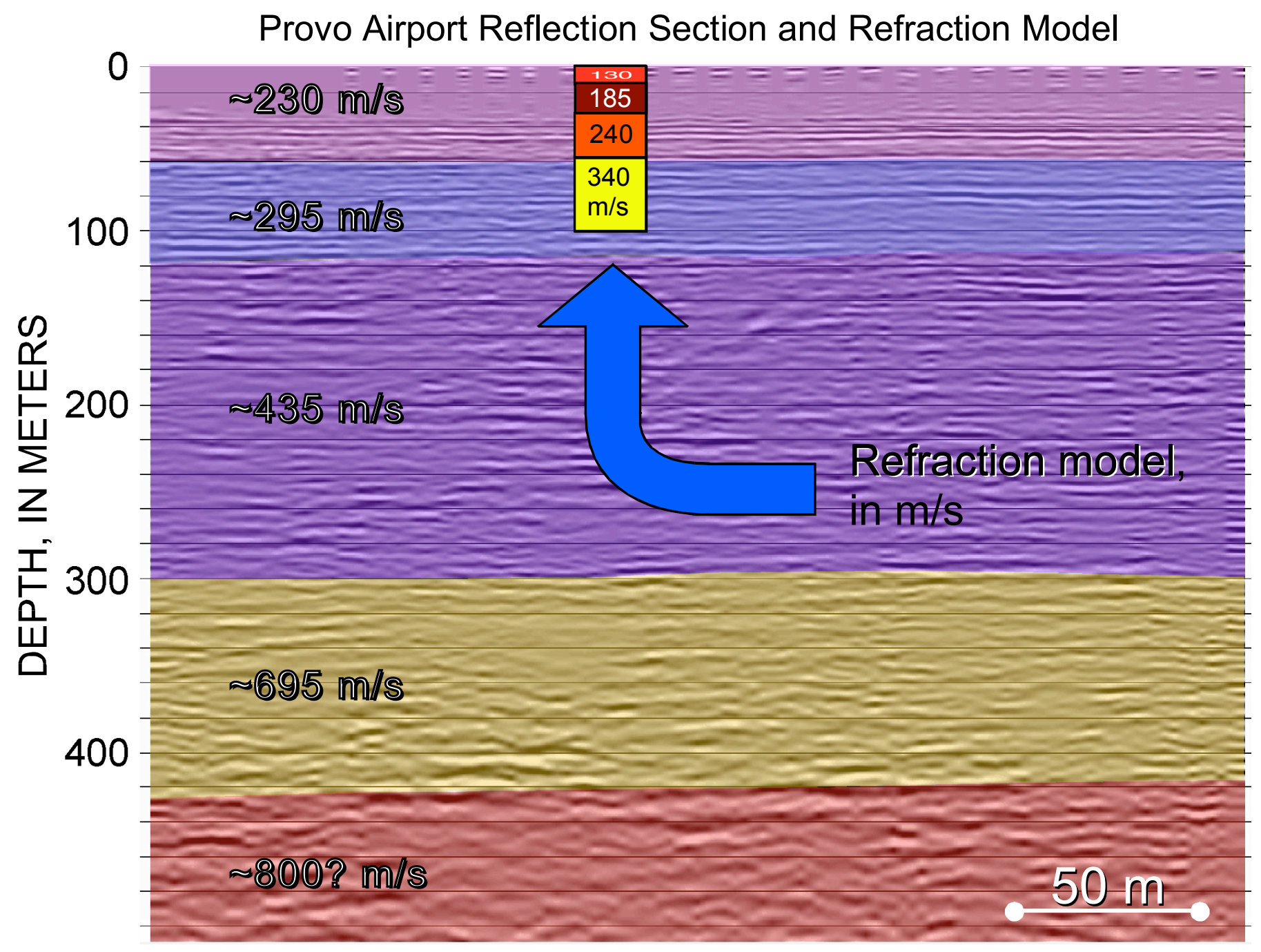

Figure 13 (B). CMP reflection stack at site PA overlain by "best" refraction model.

acquired on or near bedrock. The shear-timber Vs30 is similar to that of a linear velocity gradient model from 300 to 1675 $\mathrm{m} / \mathrm{s}$ between depths of 0 and $38 \mathrm{~m}$, as used in the weak-motion analysis of Pankow and Pechmann (2004). An alternative theoretical exponential function (J. Pechmann, written commun., 2004 ) is also shown in figure $21 \mathrm{~b}$ and has a still higher Vs30 of $760 \mathrm{~m} / \mathrm{s}$. The shear-timber model is undoubtedly most representative of the NOQ site when compared with the minivib model. The final Vp and Vs models for site NOQ are shown in figure $21 \mathrm{c}$.

\section{Summary of Vs30 and Vs100 Values}

The Vs30 values for the minivib, shear-timber and downhole sites are listed in table 1. Minivib Vs30 values in Salt Lake Valley are near the logarithmic means for Vs30 of the representative "non-rock" surface units in the Utah Geological Survey database (Ashland and McDonald, 2003). Minivib Vs30 values in Utah Valley are both on the low end for unit Q01 according to the statistics of Ashland and McDonald (2003) derived for the Salt Lake City metropolitan area. The Vs30 values for the shear-timber data on the southern side of Utah Valley decreased from $370 \mathrm{~m} / \mathrm{s}$ to $200 \mathrm{~m} / \mathrm{s}$ as sites proceeded to finer-grained deposits into the basin. These values are all within ranges for the representative site-condition units one would infer based on Ashland and McDonald (2003).

The Vs30 values from downhole results compare well to Vs30 values from the surface methods. The Vs30 for the Saltair site, listed in table 1, differs by only 2 percent from a Vs30 downhole measurement reported by Williams and others (1993) at a site roughly $2 \mathrm{~km}$ south of the minivib sounding location. The Vs30 value at a site along the Jordan River 


\section{SOURCE-SENSOR OFFSET, IN METERS}

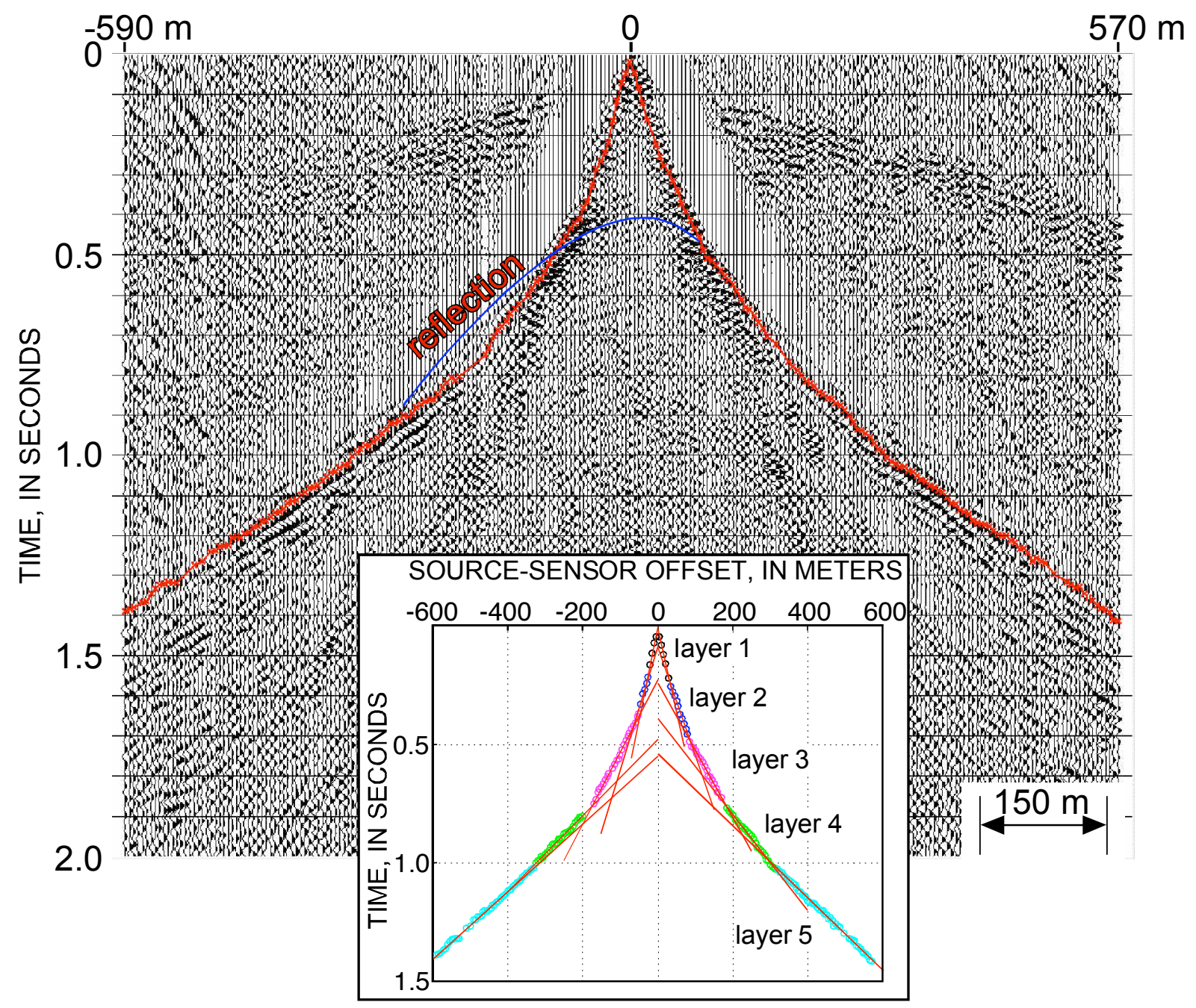

Figure 14. Traces from combined Exchange Park (EP) S-wave minivib seismic records used for refraction interpretation, sorted by source-sensor offset. Refraction picks shown by red lines. Clear reflections observed in upper $1 \mathrm{~s}$ are consistent with refraction-only model, shown in inset.

approximately $4 \mathrm{~km}$ north of the River Oaks sounding site, from Williams and others (1993), is $278 \mathrm{~m} / \mathrm{s}$. The difference is approximately 13 percent. The $\mathrm{S}$-wave downhole data near the Provo Airport are approximately $1 \mathrm{~km}$ southwest of the Provo Airport minivib site. The Vs30 values for these are $161 \mathrm{~m} / \mathrm{s}$ and $160 \mathrm{~m} / \mathrm{s}$, respectively.

Because of their greater depth of penetration, Vs100 values were calculated for the seven minivib acquisition sites only. Sites acquired on mapped Q01 deposits in Salt Lake and Utah Valleys are qualitatively similar down to a depth of over 150-m (fig. 8). Site EP on mapped Q02 deposits in Utah Valley is more similar to Q01 sites in the upper $50 \mathrm{~m}$ than to the other Q02 sites RO and SD. In general, Q03 sites are consistently higher in velocity than Q01 sites, but are not markedly different from Q02 sites at depths below approximately $30 \mathrm{~m}$. Comparing the Vs100 calculations in table 1, these qualitative observations are consistent with this mean value. At depths of $100 \mathrm{~m}$ or greater, site similarity apparently becomes more related to site-location/basin-edge distance and basin geometry than to the surface unit mapped at a given site. While Vs100 is not a standard implemented in building codes (International Building Council, 2006), it is perhaps a more meaningful value when analyzing ground motions at $1 \mathrm{~Hz}$ and less. 


\section{Site: Spanish Oaks Golf Course, Spanish Fork, Utah}

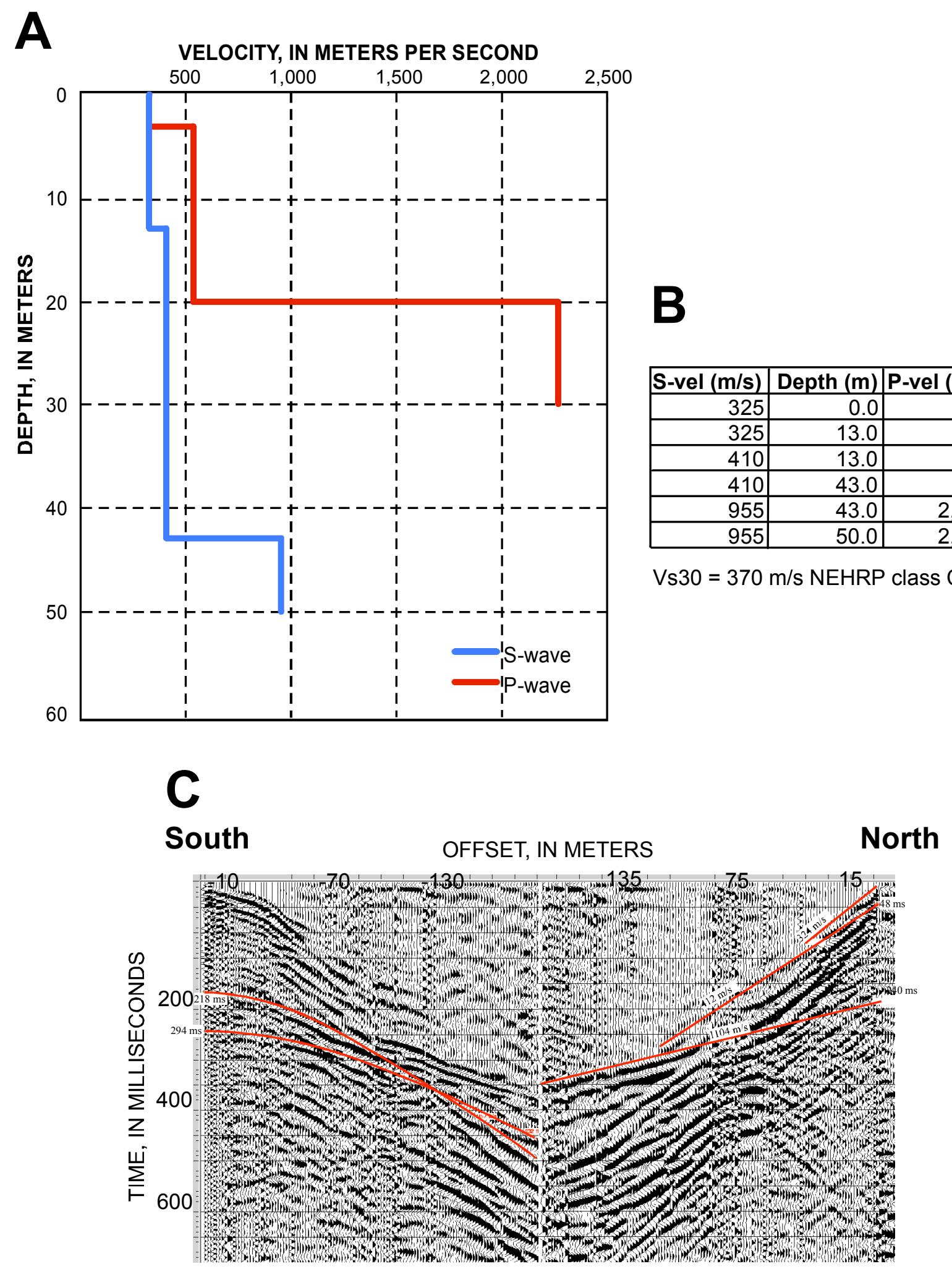

Figure 15. Spanish Oaks (SOGC) shear-timber Vs and sledgehammer Vp site. (A) Graphical display of Vs and Vp velocity structures; (B) Interpreted velocity structures in table format; (C) Representative Vs field records. Interpreted reflections and refractions are shown by red lines. 


\section{Site: Canyon Elementary, Spanish Fork, Utah}
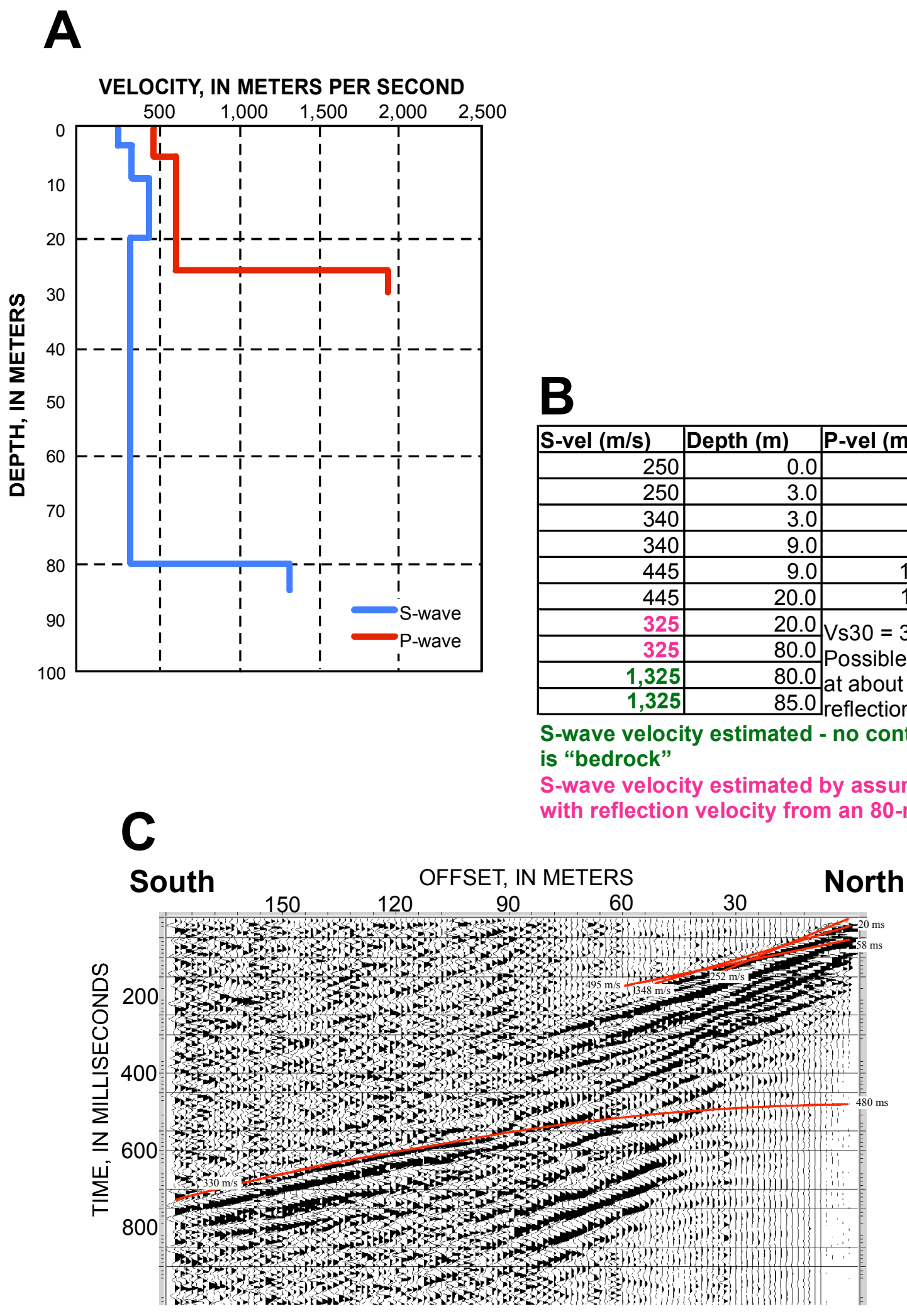

Figure 16. Spanish Fork Canyon Elementary School (SFCE) shear-timber Vs and sledgehammer Vp site. (A) Graphical display of Vs and Vp velocity structures; (B) Interpreted velocity structures in table format; (C) Representative Vs field records. Interpreted reflections and refractions are shown by red lines.

\begin{tabular}{|r|r|r|r|}
\hline S-vel (m/s) & Depth $(\mathbf{m})$ & P-vel $(\mathbf{m} / \mathbf{s})$ & Depth $\mathbf{( m )}$ \\
\hline 250 & 0.0 & 480 & 0.0 \\
\hline 250 & 3.0 & 480 & 5.0 \\
\hline 340 & 3.0 & 615 & 5.0 \\
\hline 340 & 9.0 & 615 & 26.0 \\
\hline 445 & 9.0 & 1,945 & 26.0 \\
\hline 445 & 20.0 & 1,945 & 30.0 \\
\hline 325 & 20.0 & Vs $30=350 \mathrm{~m} / \mathrm{s}$ NEHRP class D \\
\hline 325 & 80.0 & Possible strong site resonance \\
\hline 1,325 & 80.0 & at about 1.0 Hz (based on \\
\hline 1,325 & 85.0 & reflection time from rock)
\end{tabular}

S-wave velocity estimated - no control and assuming it is "bedrock"

S-wave velocity estimated by assuming a velocity that fits with reflection velocity from an 80-m deep layer 


\section{Site: Clark Park, Spanish Fork, Utah}

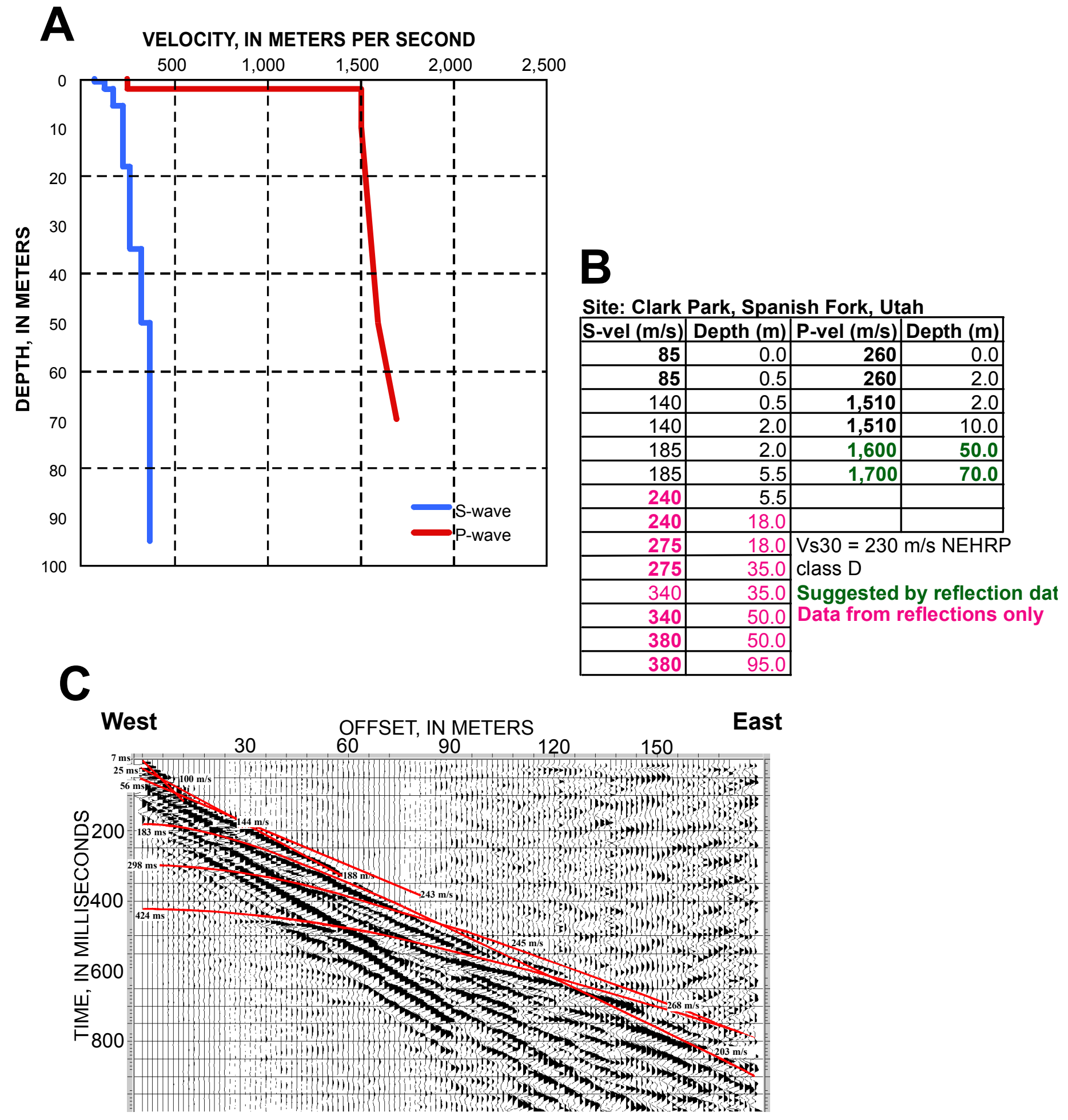

Figure 17. Spanish Fork Clark Park (SFCP) shear-timber Vs and sledgehammer Vp site. (A) Graphical display of Vs and Vp velocity structures; (B) Interpreted velocity structures in table format; (C) Representative Vs field records. Interpreted reflections and refractions are shown by red lines. 


\section{Site: Spanish Fork Airport, Spanish Fork, Utah}

A

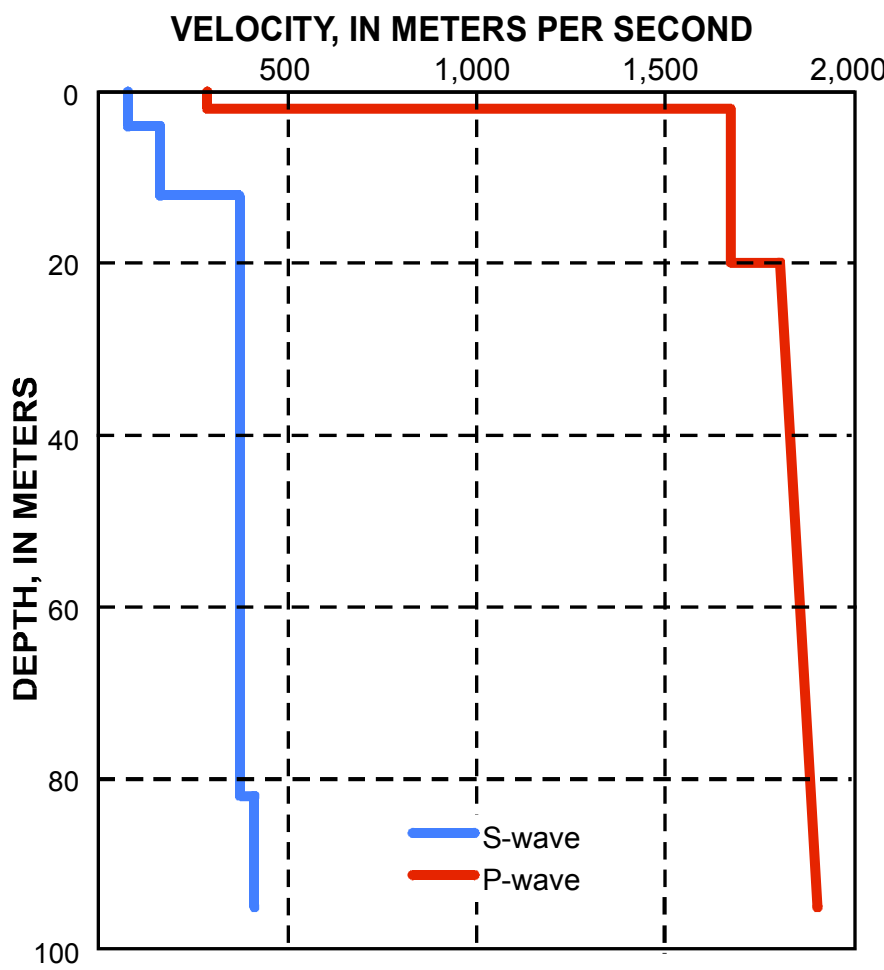

B

\begin{tabular}{|r|r|r|r|}
\hline S-vel (m/s) & Depth $(\mathbf{m})$ & P-vel (m/s) & Depth $(\mathbf{m})$ \\
\hline 78 & 0.0 & 285 & 0.0 \\
\hline 78 & 4.0 & 285 & 2.0 \\
\hline 160 & 4.0 & 1,670 & 2.0 \\
\hline 160 & 12.0 & 1,670 & 20.0 \\
\hline 370 & 12.0 & 1,800 & 20.0 \\
\hline 370 & 82.0 & 1,900 & 95.0 \\
\hline 410 & 82.0 & & \\
\hline 410 & 95.0 & & \\
\hline
\end{tabular}

Unreversed profile

Layer not observed from south end

Vs30 $=200 \mathrm{~m} / \mathrm{s}$ NEHRP class $D$

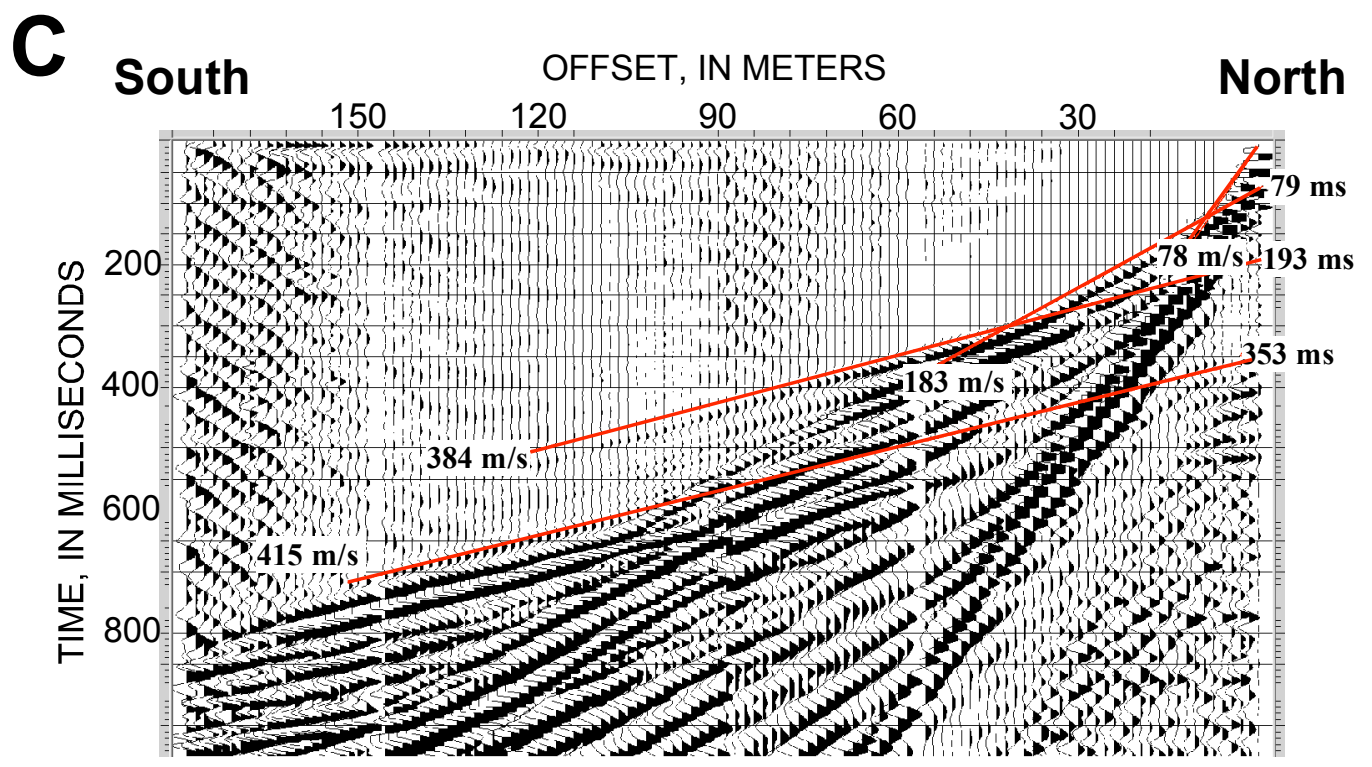

Figure 18. Spanish Fork Airport (SFA) shear-timber Vs and sledgehammer Vp site. (A) Graphical display of Vs and Vp velocity structures; (B) Interpreted velocity structures in table format; (C) Representative Vs field records. Interpreted reflections and refractions are shown by red lines. 


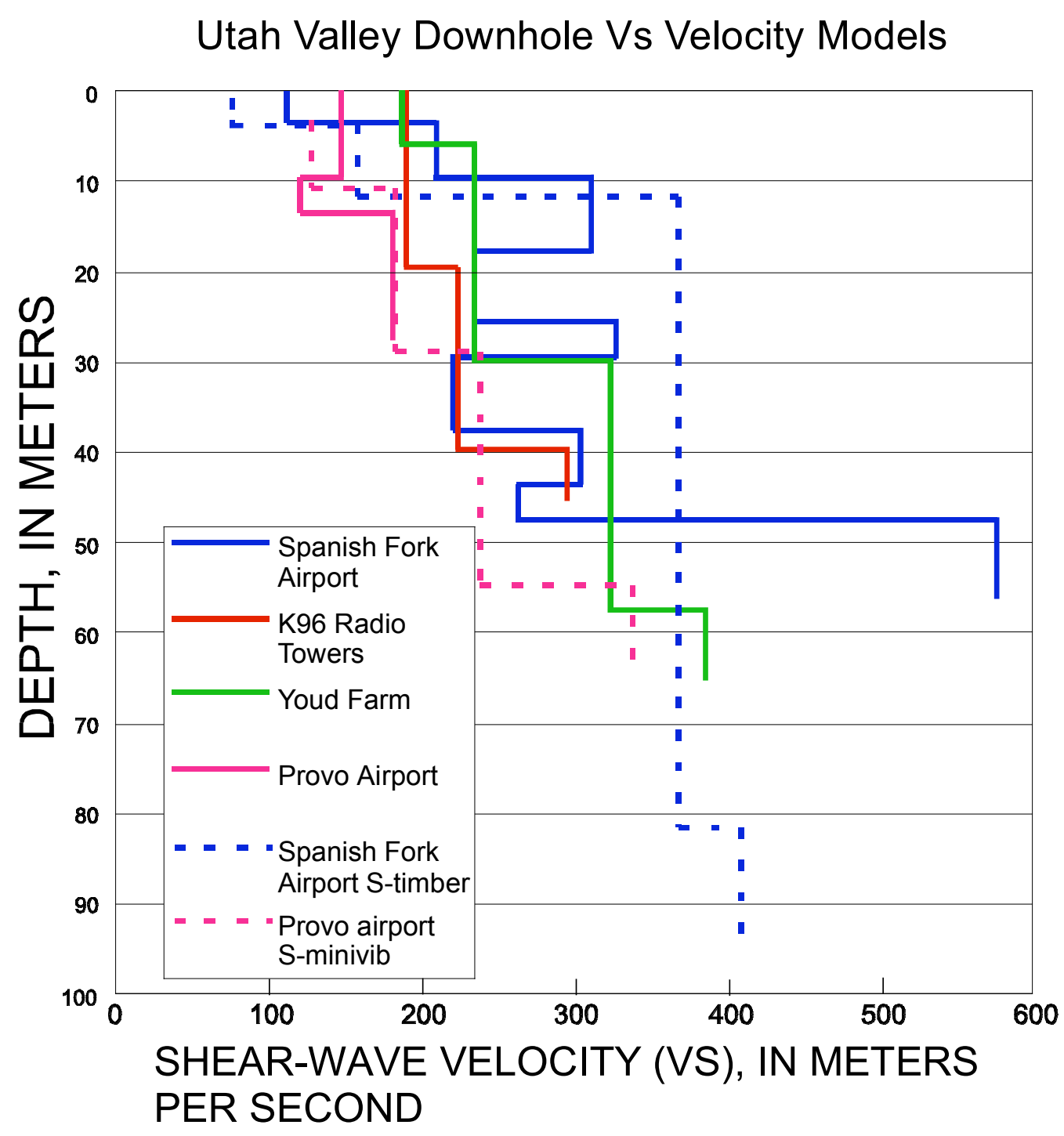

Units for all tables:

Depth, in meters

$\mathrm{Vs}$, in meters per second

\begin{tabular}{cc}
\multicolumn{2}{c}{ K96 } \\
\hline Depth & Vs \\
0 & 192 \\
20 & 192 \\
20 & 227 \\
40 & 227 \\
40 & 297 \\
46 & 297
\end{tabular}

Provo Airport

\begin{tabular}{cc}
\hline Depth & Vs \\
0 & 150 \\
10 & 150 \\
10 & 124 \\
14 & 124 \\
14 & 184 \\
28 & 184
\end{tabular}

Spanish Fork Airport

Depth

0

$4 \quad 212$

$10 \quad 212$

$10 \quad 314$

$18 \quad 314$

$18 \quad 237$

$26 \quad 237$

$26 \quad 330$

$30 \quad 330$

$30 \quad 223$

$38 \quad 223$

$38 \quad 306$

$44 \quad 306$

$44 \quad 266$

$48 \quad 266$

$48 \quad 579$

$56.6 \quad 579$

Youd Farm

Depth Vs

$0 \quad 187$

$6 \quad 187$

$6 \quad 234$

$30 \quad 234$

$30 \quad 326$

$58 \quad 326$

$58 \quad 388$

$65.8 \quad 388$

Figure 19. S-velocity models for the four downhole S-wave soundings in Utah Valley are shown as solid lines on graph. Dashed pink line is Provo Airport S-minivib result for comparison with Provo Airport downhole result. Dashed blue line is S-timber Spanish Fork Airport result for comparison with nearby downhole result. Velocity-depth models, in table form, are listed to right of diagram. 

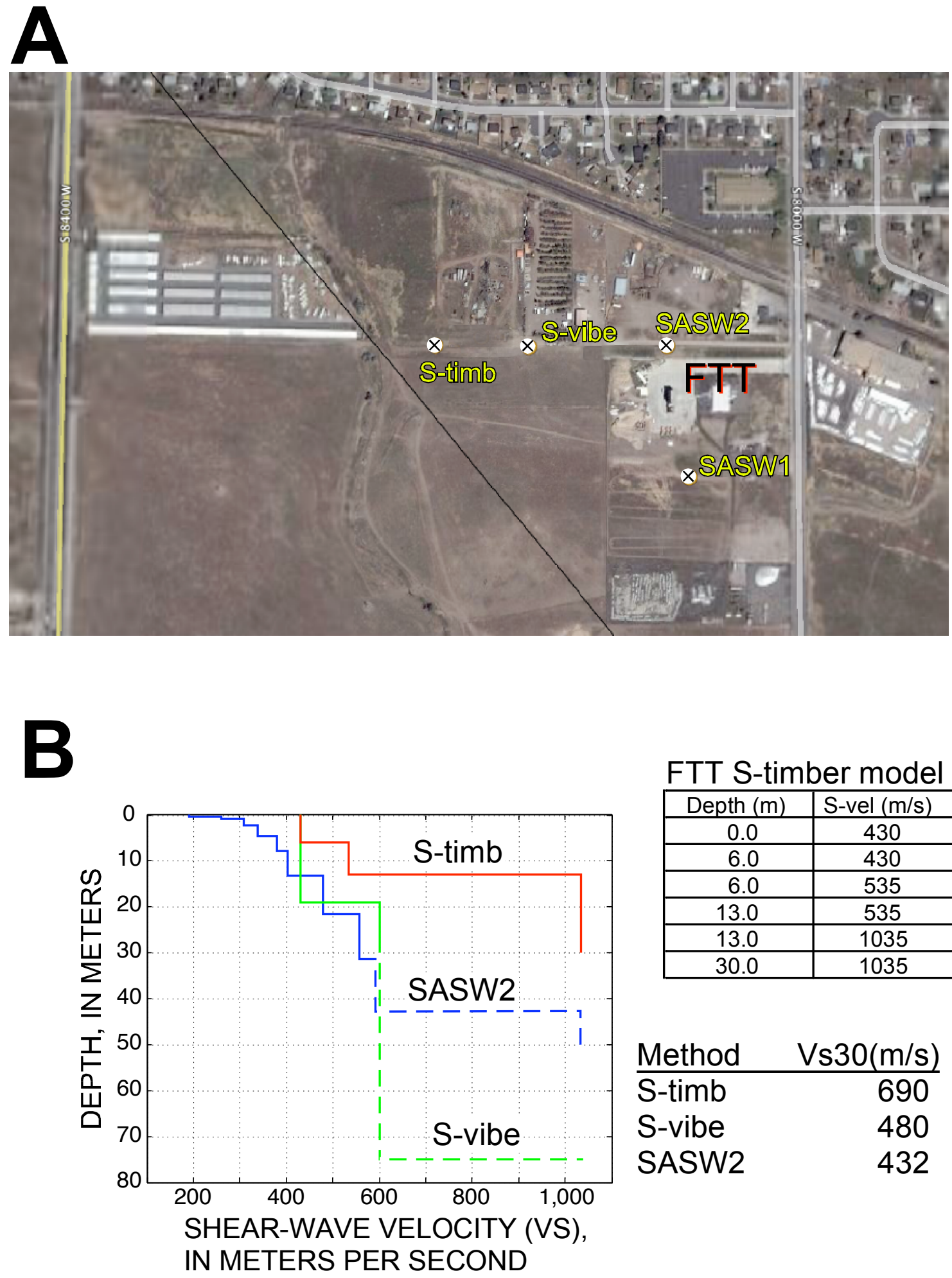

FTT S-timber model

\begin{tabular}{|c|c|}
\hline Depth $(\mathrm{m})$ & S-vel $(\mathrm{m} / \mathrm{s})$ \\
\hline 0.0 & 430 \\
\hline 6.0 & 430 \\
\hline 6.0 & 535 \\
\hline 13.0 & 535 \\
\hline 13.0 & 1035 \\
\hline 30.0 & 1035 \\
\hline
\end{tabular}

Method Vs30(m/s)

S-timb $\quad 690$

S-vibe

480

SASW2

432

Figure 20. Fire training tower (FTT) comparison of minivib, shear-timber, and SASW results. (A) Locations of array midpoints for shear-timber (S-timb), minivib (S-vibe), first SASW (SASW1), and second SASW (SASW2) investigations. SASW results from J. Berry and J. Bay (Utah State University, written commun., 2006). (B) Vsdepth models from shear-timber (red), minivib (green), and SASW2 (blue) investigations. Dashed lines indicate a decreased confidence in the interpretation. 
A

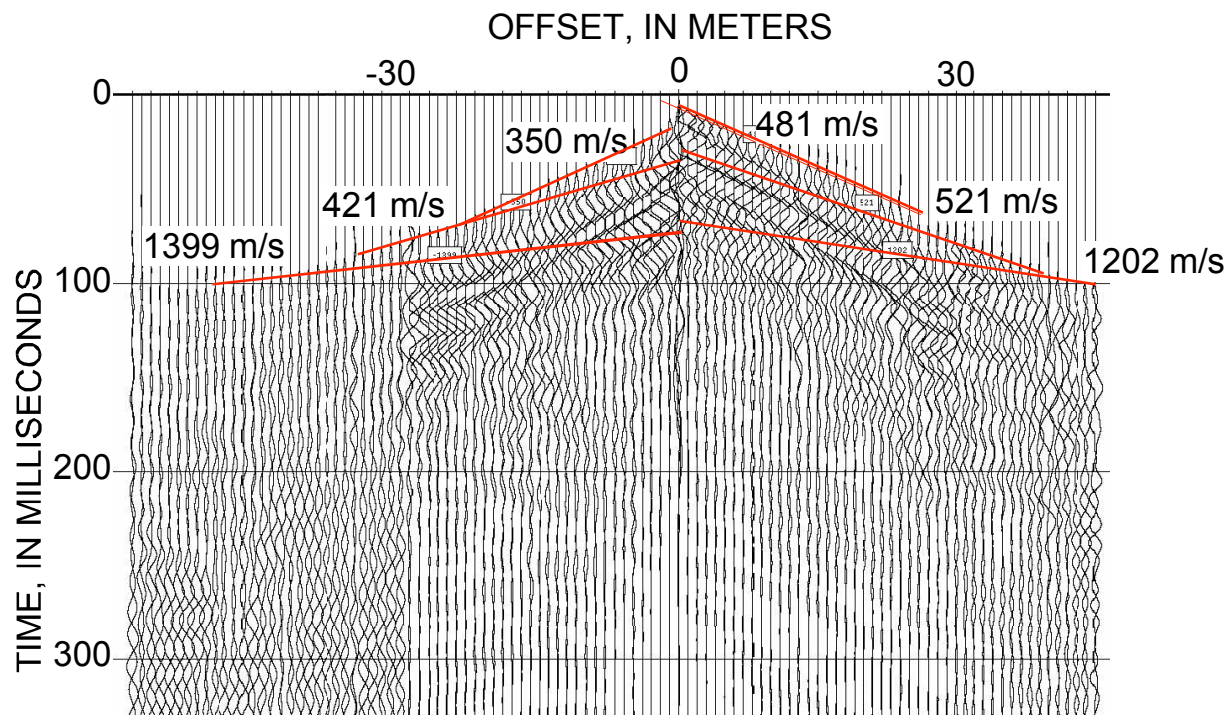

\section{B}

$\mathscr{\sim}$

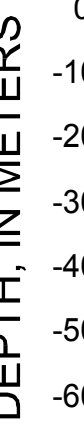

red: S-timber

$\mathrm{Vs} 30=660 \mathrm{~m} / \mathrm{s}$

green: S-minivib

$\mathrm{Vs} 30=620 \mathrm{~m} / \mathrm{s}$

blue: theoretical exponential

$\mathrm{Vs} 30=760 \mathrm{~m} / \mathrm{s}$

blue dash: theoretical linear

$\mathrm{Vs} 30=670 \mathrm{~m} / \mathrm{s}$

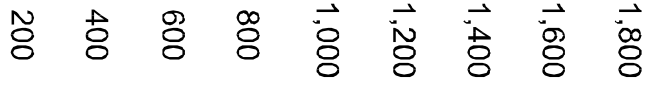

SHEAR-WAVE VELOCITY (VS), IN METERS PER SECOND

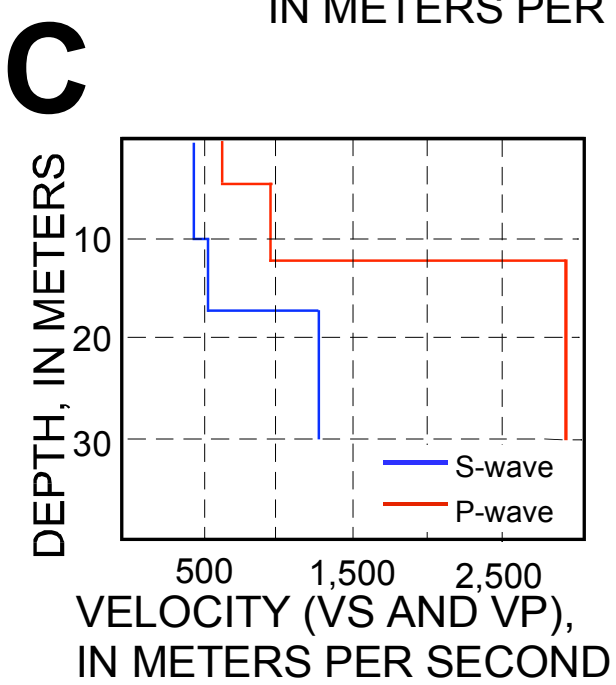

NOQ S-timber model
\begin{tabular}{|c|c|}
\hline Depth $(\mathrm{m})$ & S-vel $(\mathrm{m} / \mathrm{s})$ \\
\hline 0.0 & 450 \\
\hline 10.0 & 450 \\
\hline 10.0 & 535 \\
\hline 17.0 & 535 \\
\hline 17.0 & 1,290 \\
\hline 30.0 & 1,290 \\
\hline
\end{tabular}

NOQ P-wave model

\begin{tabular}{|l|l|}
\hline Depth $(\mathrm{m})$ & $P$-vel $(\mathrm{m} / \mathrm{s})$ \\
\hline 0.0 & 650 \\
\hline 4.0 & 650 \\
\hline 4.0 & 970 \\
\hline 12.0 & 970 \\
\hline 12.0 & 2,950 \\
\hline 30.0 & 2,950 \\
\hline
\end{tabular}

Figure 21. (A) Shear-timber data acquired at site NOO and interpreted velocity-depth structure. Data are shown as reversedpolarity overlay to emphasize clean first arrival times. Red lines show refraction interpretation. (B) Comparison of minivib and shear-timber results with theoretical linear and exponential velocity functions. Vs30s of shear-timber and linear velocity-depth model are very similar at 660-670 m/s. (C) Graph showing Vs and Vp result from respective sledgehammer-source data. N00 shear-timber velocity-depth model and P-wave velocity-depth model are shown in table format to right of figure. 


\section{References Cited}

Arnow, T., Van Horn, R., and LaPray, R., 1970, The preQuaternary surface in the Jordan valley, Utah: U.S. Geological Survey Professional Paper 700-D, p. D257-D261.

Ashland, F.X., and McDonald, G.N., 2003, Interim map showing shear-wave velocity characteristics of engineering geologic units in the Salt Lake City, Utah, metropolitan area: Utah Geological Survey Open-File Report 424, scale 1:75,000.

Hill, J., Benz, H.M., Murphy, M., and Schuster, G.T., 1990, Propagation and resonance of SH waves in the Salt Lake Valley, Utah: Bulletin Seismological Society of America, v. 80 , p. $23-42$.

International Building Council, 2006, International Building Code for 2006, International Code Council, 679 p.

Kobayashi, N., 1959, A method of determining the underground structure by means of SH waves: Zisin, v. 12, p. 19-24.

Mooney, H.M., 1984, Handbook of engineering geophysics (v. 1)-seismic: Minneapolis, Minnesota, Bison Instruments, Inc.

Olsen, K.B., Pechmann, J.C., and Schuster, G.T., 1995, Simulation of 3D elastic wave propagation in the Salt Lake basin: Bulletin Seismological Society of America, v. 85, p. 1,688-1,710.

Pankow, K.L., and Pechmann, J.C., 2004, Determination of low-strain site amplification factors in the Salt Lake Valley, Utah, using ANSS data: EOS, v. 85, no. 47, fall meeting supplement, S42A-0974.
Radkins, H.C., 1990, Bedrock topography of the Salt Lake Valley, Utah, from constrained inversion of gravity data: Salt Lake City, Utah, University of Utah Master's thesis, 59 p.

Solomon, B.J., Storey, N., Wong, I., Silva, W., Gregor, N., Wright, D., and McDonald, G., 2004, Earthquake-hazards scenario for a M7 earthquake on the Salt Lake City segment of the Wasatch fault zone, Utah CD-ROM: Salt Lake City, Utah, Utah Geological Survey, Special Study Report 111, 59 p., 6 pls. (scale 1:250,000).

Stephenson, W.J., Louie, J.N., Pullammanappallil, S., Williams, R.A., and Odum, J.K., 2005, Blind shear-wave velocity comparison of ReMi, and MASW results with boreholes to $200 \mathrm{~m}$ in the Santa Clara Valley-Implications for earthquake ground motion assessment: Bulletin Seismological Society of America, v. 95, p. 2,506-2,516.

Tinsley, J.C., King, K.W., Trumm, D.A., Carver, D.L., and Williams, R.A., 1991, Geologic aspects of shear-wave velocity and relative ground response in Salt Lake Valley, Utah, in McCalpin, J.P., ed., Proceedings of the 1991 Annual Symposium on Engineering Geology \& Geotechnical Engineering, no. 27, p. 25-1-25-12.

Williams, R.A., King, K.W., and Tinsley, J.C., 1993, Site response estimates in the Salt Lake Valley, Utah, from borehole seismic velocities: Bulletin Seismological Society of America, v. 83, p. 862-889.

Williams, R.A., Stephenson, W.J., and Odum, J.K., 2003, Comparson of P- and S-wave velocity profiles obtained from surface seismic refraction/reflection and downhole data: Tectonophysics, v. 368, p. 71-88. 